\title{
Sociólogos Rurais, Modernização e Ideais de Comunidade na América Latina: 0 Caso do Office of Foreign Agricultural Relations (1930 - 1940)
}

\author{
Thiago da Costa Lopes ${ }^{1}$ \\ ${ }^{1}$ Doutor em História das Ciências e da Saúde pela Fundação Oswaldo Cruz (COC/Fiocruz). Rio de \\ Janeiro, Brasil. \\ E-mail: lopes_47@hotmail.com \\ Marcos Chor Maio ${ }^{2}$ \\ ${ }_{2}^{2}$ Pesquisador e professor do Programa de Pós-graduação em História das Ciências e da Saúde da Casa de \\ Oswaldo Cruz, Fundação Oswaldo Cruz (COC/Fiocruz). Rio de Janeiro, Brasil. \\ E-mail: chormaio@gmail.com
}

\section{INTRODUÇÃO}

Jos anos 1940, as trocas científicas entre as Américas, especialmente pelas políticas de cooperação técnica dos EUA a cargo do Office of Foreign Agricultural Relations (OFAR), escritório de assuntos internacionais do Departamento de Agricultura (USDA). Durante a Segunda Guerra Mundial e nos anos posteriores ao conflito, o OFAR empregou sociólogos rurais em atividades de pesquisa e aconselhamento técnico em programas de educação, saúde, habitação e extensão rural em diferentes países da América Latina. Com larga experiência nos programas de engenharia social do New Deal agrário de Roosevelt, postos em marcha nos anos 1930, esses cientistas sociais buscaram construir, no contexto da Política de Boa Vizinhança, um espaço de atuação nas Américas capaz de: a) expandir a rede de interlocutores e praticantes da Sociologia Rural que vinha se institucionalizando nos EUA a partir do ensino agrícola superior (agricultural colleges), das estações agrícolas experimentais e dos serviços estaduais de extensão rural; b) ampliar, para além do território norte-americano, o escopo de suas investigações sobre o mundo rural e c) veicular, além-fronteiras, os ideais reformadores que informavam sua atuação profissional, que apontavam para 
um mundo rural de pequenas comunidades de famílias fazendeiras de classe média que gozassem de relativa independência socioeconômica e aptas ao exercício da cidadania e do autogoverno.

Os sociólogos rurais recrutados por Washington provinham de conhecidos círculos acadêmicos e governamentais norte-americanos e empreenderam missões de estudo em diferentes países: T. Lynn Smith (Brasil, Colômbia e El Salvador); Carl Taylor (Argentina); Nathan Whetten (México); Charles Loomis (Peru); Lowry Nelson (Cuba) e Olen Leonard (Bolívia). Mesmo antes da entrada oficial dos EUA na guerra, com a escalada das tensões internacionais e a crescente preocupação em garantir uma zona de influência hemisférica que se mantivesse ao abrigo das forças beligerantes na Europa e na Ásia, o governo norte-americano já sentia necessidade de preencher as lacunas existentes no país quanto a um conhecimento mais aprofundado e preciso acerca dos povos vivendo ao sul do Rio Grande (Salvatore, 2016). Este era um passo considerado importante para que os EUA se estabelecessem como uma espécie de bússola a guiar as demais nações do continente, em um exercício de hegemonia que privilegiava, no lugar das antigas táticas de intervenção militar, a construção de uma imagem positiva e prestigiosa do país enquanto liderança política e técnico-científica das Américas.

À maneira de diferentes cientistas sociais que realizaram pesquisas na América Latina durante a primeira metade do século XX, os sociólogos rurais desempenharam importante papel na interpretação e na tradução das culturas e formas de vida social da região em uma linguagem e em um conjunto de categorias inteligíveis para o Estado e para a sociedade norte-americana. As condições de trabalho e as técnicas produtivas prevalecentes entre as populações rurais da região haviam se tornando um dos pontos sensíveis na política externa de Washington. Segundo o entendimento que se estabeleceu entre representantes do governo Roosevelt, os conflitos internacionais, que ameaçavam interromper as trocas comerciais tradicionais da América Latina com a Europa, demandavam programas bem-informados de cooperação agrícola interamericana capazes de garantir um grau relativo de autossuficiência econômica do continente. Com base no argumento de que suas pesquisas deveriam anteceder e orientar as políticas de assistência técnica para a América Latina, os sociólogos rurais conduziram estudos sobre as condições sociais e culturais em que transcorria a atividade econômica das zonas rurais de países latino-americanos. Ambiciona- 
vam traçar estratégias para a transmissão de conhecimento técnico-científico (extensão rural) capaz de elevar a produtividade econômica e os padrões de vida das populações locais, consideradas doentes, apáticas, presas a métodos primitivos de trabalho, politicamente passivas e sujeitas a relações de dependência típicas do regime da plantation.

Embora o espraiamento da sociologia rural para além dos EUA tenha ocorrido na esteira da política externa norte-americana, a disciplina e seus praticantes dificilmente podem ser vistos como meros instrumentos utilizados na persecução dos interesses geopolíticos do país. Em realidade, o valor prático das ciências sociais para os quadros técnicos de Washington não estava dado de antemão, mas teve de ser conquistado a partir de um complexo processo de negociação e convencimento. Os próprios sociólogos rurais se envolveram nessa tarefa, buscando costurar a agenda do governo norte-americano com os interesses científicos e políticos que perseguiam domesticamente.

Da mesma forma, ainda que a ideia de superioridade técnica e científica dos EUA constituísse ponto pacífico da visão que orientou o trabalho desses cientistas sociais na América Latina, a avaliação que fizeram das possibilidades de reforma nas condições de vida de suas populações rurais se distanciava das leituras mais conhecidas sobre o desenvolvimento produzidas pelas ciências sociais norte-americanas, tal como aquela presente na teoria da modernização. Subjacente à ideia de desenvolvimento se encontrava uma visão teleológica da história segundo a qual os países periféricos, no decurso das mudanças modernizadoras, tenderiam a convergir para um modelo de sociedade de massas, de tipo urbano-industrial, cuja expressão mais bem acabada eram os EUA ${ }^{1}$. Conforme argumentamos, os sociólogos rurais, informados por um pensamento de matriz comunitarista, não apenas se afastaram de perspectivas triunfalistas e otimistas sobre a modernidade, como enxergaram a América Latina como palco de experimentos societais originais. A aposta era que os países da região pudessem enveredar por formas mais comunitárias de desenvolvimento e contornar os efeitos deletérios da modernização nos EUA, como o individualismo agudo e a proletarização dos agricultores. Nesse caso, a atmosfera intelectual do New Deal, marcada pelo descontentamento com os excessos do capitalismo liberal nos EUA, contribuiu para que esses cientistas sociais, não se limitando ao registro de lacunas e carências, lançassem muitas vezes um olhar de aprovação para os vizinhos do Sul. Assinalavam, assim, os potenciais das culturas e das sociedades latino-americanas para 
a construção de uma modernidade rural de novo tipo. Não que não estivesse em curso, nesse processo, a construção discursiva da América Latina como "o outro" dos EUA - o que implicava que esta fosse vista de modo unitário e definida em muitos aspectos em oposição àquele país (Feres Jr., 2005). Todavia, ainda que estereotipadas, as imagens sobre a região frequentemente adquiriram sentido positivo na pena de diversos autores estadunidenses (Pike, 1985). Ademais a disposição em identificar o que haveria de construtivo na experiência histórica dos povos latino-americanos levou os sociólogos rurais a leituras das obras de intelectuais locais que foram decisivas para a elaboração de seus diagnósticos sobre a região.

Examinar a forma como a sociologia rural avaliou os desafios postos para a modernização da vida rural na América Latina pode nos ajudar a compreender melhor as visões sobre o desenvolvimento que caracterizaram a primeira metade do século XX e os diferentes constructos teóricos produzidos pelas ciências sociais a respeito dessa mudança. Essa sociologia também teve desdobramentos importantes no pós-Segunda Guerra, sobretudo em programas de desenvolvimento de comunidade levados a cabo em áreas rurais e pobres das periferias do mundo, em países como Brasil, China e Índia, na esteira das políticas de cooperação técnica dos EUA e de organismos multilaterais como as Nações Unidas (Gilbert, 2015; Immerwahr, 2015, Raper, 1954). No Brasil, José Arthur Rios, egresso das primeiras turmas da Faculdade Nacional de Filosofia da Universidade do Brasil (atual UFRJ), e ex-aluno de T. Lynn Smith na Universidade Estadual da Louisiana, abraçou a agenda reformadora e os métodos de pesquisa da sociologia rural a partir de sua atuação em órgãos de educação e saúde do governo brasileiro (Lopes, 2020). $\mathrm{O}$ interesse investigativo em compreender a estrutura dos pequenos grupos das zonas rurais, que constituía o objeto por excelência desses estudiosos, também pode contribuir para um entendimento mais nuançado dos chamados "estudos de comunidade", que, no Brasil dos anos 1940 e 1950, debruçaram-se sobre diferentes localidades rurais do país². Pode nos fornecer, ademais, aportes para analisar como a abordagem comunitarista foi recepcionada pelas gerações posteriores de antropólogos e sociólogos que retomaram o problema da "comunidade" e do "rural" na sociedade brasileira; a exemplo dos estudos sobre campesinato levados a cabo por pesquisadores do Museu Nacional, nos anos 1970 (Carvalho, 2015). Na Colômbia, o sociólogo Orlando Fals Borda, após estudar sociologia rural com Lowry Nelson e T. Lynn Smith, tornou-se um dos mais conhecidos interlocutores desse filão das 
ciências sociais norte-americanas; ainda que tenha assumido posições epistemológicas bastante críticas às matrizes teóricas do Hemisfério Norte (Bringel, 2016; Moreno, 2017).

Nas próximas páginas, analisaremos as circunstâncias que levaram os sociólogos rurais a ampliar o escopo de suas pesquisas e incluir os países latino-americanos em sua agenda investigativa. Nesse caso, consideramos o modo como procuraram, no contexto da Política de Boa Vizinhança, legitimar seu campo de atuação e conhecimento junto às agências governamentais encarregadas dos programas de cooperação com os vizinhos ao sul do continente. Em seguida, examinaremos como as visões desses sociólogos sobre as populações rurais latino-americanas estiveram integradas a um ambiente intelectual simpático ao universo cultural dos povos da região e característico dos setores reformadores do New Deal. Enfocando o trabalho de T. Lynn Smith no Brasil, indicamos como as nações latinas foram pensadas não apenas como representantes de uma fase rudimentar da produção agrícola a ser superada com a difusão de técnicas modernas, mas também como sociedades cuja história poderia apontar caminhos alternativos para a modernização do mundo rural. No diagnóstico sociológico de Smith é possível avaliar, igualmente, em que medida tradições locais de conhecimento influíram sobre sua visão acerca do desenvolvimento das comunidades rurais brasileiras.

\section{A SOCIOLOGIA RURAL NOS EUA E A POLÍTICA DE BOA VIZINHANÇA}

Nos anos 1930, com o recrudescimento das tensões na Europa e em face do que era percebido como a crescente ameaça nazifascista na América Latina, as Ciências Sociais se tornaram um dos elementos da aproximação diplomática do Governo Roosevelt com os países da região. No contexto da Política de Boa Vizinhança, sociólogos e antropólogos agiram como promotores das relações culturais entre os EUA e seus vizinhos ao sul, com base especialmente no incremento das trocas e da cooperação acadêmica. Nesse período, as ciências em geral foram vistas pelos estadunidenses como canal privilegiado para o estreitamento das relações com os países latino-americanos na medida em que sua linguagem, considerada como universal, seria capaz de produzir conhecimento sobre as diferentes sociedades e culturas da região. De acordo com T. Lynn Smith, o empreendimento científico, contornando juízos de valor depreciativos e visões chauvinistas ou eurocêntricas, poderia contribuir para uma apreciação mútua de pontos de vista entre 
os povos das Américas ${ }^{3}$. Segundo o discurso oficial de Washington e dos agentes governamentais envolvidos com os primórdios da política de relações culturais, a ciência era produto da atividadede sábios e acadêmicos que conseguiriam se manter à distância das preocupações e interesses mais imediatos das nações. Tal argumento buscava distinguir o esforço norte-americano em incrementar as trocas científicas com os países do continente - considerado como legítimo - das estratégias mais agressivas no terreno da diplomacia cultural - de propaganda, tradicionalmente identificadas às potências europeias (Espinosa, 1977; Graham, 2015; Ninkovich, 1981). Essa compreensão acerca da ciência não significava, evidentemente, que preocupações de ordem geopolítica estivessem ausentes da diplomacia cultural norte-americana do período, especialmente a partir de 1940, quando Roosevelt instituiu o Office of the Coordinator of Inter-American Affairs, chefiado por Nelson Rockefeller. Com o avanço das tropas de Hitler na Europa, os EUA sentiam cada vez mais premente a necessidade de neutralizar a ascendência e o prestígio que a Alemanha possuía entre setores da elite e da intelectualidade latino-americana (Smith, 2017).

O caso do Institute of Social Anthropology (ISA) se tornou emblemático dos esforços de cooperação inter-americana, no campo das Ciências Sociais, no contexto da Política de Boa Vizinhança. Criado em 1943, como divisão do Department of American Ethnology da Smithsonian Institution, com sede em Washington, D. C., o ISA esteve inicialmente voltado para a promoção de atividades de ensino e pesquisa em países latino-americanos com base em acordos de cooperação entre os EUA e instituições locais (Castro, 2010; Faulhaber, 2011; Figueiredo, 2009; Price, 2008). As atividades que o sociólogo Donald Pierson vinha realizando em São Paulo desde 1939 constituíram uma das referências para a organização e a expansão da atuação do ISA, então sob a direção do antropólogo Julian Steward, em países como Colômbia, Peru e México (Pierson, 1987). A expectativa de quadros como Pierson era, a um só tempo, impulsionar o desenvolvimento científico da sociologia em países como o Brasil e ampliar o conjunto de conhecimentos empíricos sobre a região.

Ainda que não contasse, como o ISA, com uma estrutura organizacional própria nem com um programa de treinamento de alunos e cooperação acadêmica em bases sistemáticas, o trabalho desenvolvido a partir do OFAR foi igualmente ambicioso na extensão de sua agenda investigativa em diferentes regiões da América Latina. Unidade de ligação entre o Departamento de Estado e o Departamento de Agricul- 
tura, o OFAR era responsável por coletar informações sobre a produção agrícola e os mercados internacionais e estabelecer acordos comerciais com outros países em torno da importação e exportação de commodities. Uma de suas incumbências era acompanhar a variação dos preços dos produtos agrícolas no mundo e avaliar seus impactos para a atividade econômica dos fazendeiros norte-americanos ${ }^{4}$. Desde o início de suas atividades no órgão, os sociólogos rurais tiveram que conciliar seus interesses científicos e profissionais com demandas práticas de engenharia social provenientes das agências governamentais. Deveriam atuar simultaneamente como cientistas e experts capazes de orientar políticas de assistência técnica nos campos da educação, da saúde e da agricultura que vieram à luz a partir de acordos de cooperação entre os EUA e as demais nações do continente durante a guerra ${ }^{5}$. Tal operação de "costura" de interesses não era estranha aos sociólogos rurais, acostumados, em sua atuação profissional nos EUA, a sintonizar a formulação e a condução dos estudos que empreendiam às demandas práticas do corpo de burocratas de Washington e das estações agrícolas experimentais distribuídas pelos diferentes estados da federação.

Do ponto de vista de seus conteúdos e objetos de investigação, como as formas de agrupamento humano do campo, a sociologia rural guardava o forte acento prático que animou os primeiros nomes associados à disciplina nos EUA - estreitamente ligados ao movimento reformador, do começo do século XX, conhecido como Country Life Movement. Essa orientação foi reforçada pelo próprio processo de institucionalização da sociologia rural, que cresceu em número de praticantes e pesquisas e ganhou espaço nas universidades graças, em grande medida, ao complexo constituído pelos land-grant colleges, as estações agrícolas experimentais e os serviços de extensão rural ${ }^{6}$. A criação, em fins da década de 1910, da Division of Farm Population and Rural Life, que passou a incorporar a expertise de sociólogos rurais às atividades de estudo e planejamento do Departamento de Agricultura, assim como o trabalho de pesquisa sociológica que começou a ser realizado nas estações agrícolas nos anos seguintes (Larson e Zimmerman, 2003), consolidaram o espírito prático e reformador da disciplina.

O processo de construção do campo da sociologia rural não foi, contudo, destituído de tensões. À medida que pleiteavam um lugar na cidadela da ciência, seus praticantes foram confrontados pelo ethos profissional do establishment da comunidade acadêmica de sociólogos, representado pela American Sociological Society. Nos anos 1920 e 1930, 
a associação se inclinava cada vez mais para os ideais de uma ciência pura, centrada no avanço teórico a partir da pesquisa empírica, manifestando sérias reservas quanto ao antigo ímpeto reformista das disciplinas sociais e suas conexões com a intervenção e a política. Embora representantes das gerações que então começavam a se estabelecer, a exemplo de Smith (1940b), tenham procurado armar a sociologia rural de todos os critérios capazes de garantir sua cientificidade, a tendência "praticista" permaneceu no interior da disciplina. Deste modo, certa ambivalência na definição de sua natureza (se uma ciência básica ou aplicada) tornou-se constitutiva da história da sociologia rural, que, ademais, acabou assumindo uma posição subordinada e marginal no universo acadêmico norte-americano (Loomis, 1979).

Por outro lado, as tradicionais vinculações da sociologia rural com o mundo das políticas públicas impulsionaram a produção intelectual e a trajetória profissional de seus praticantes. Foi o que ocorreu durante o New Deal, momento em que o governo central dos EUA se abriu para planos mais ambiciosos de reforma e intervenção social. Os programas de alívio econômico e de assistência social instituídos por Roosevelt para fazer frente aos efeitos da Grande Depressão, especialmente entre as populações rurais empobrecidas, acabaram abrindo espaço para os praticantes da disciplina. Nesse momento, uma série de agências foram criadas, tais como a como a Federal Emergency Relief Administration, a Civil Work Administration, a Agricultural Adjustment Administration e a Resettlement Administration. Tais iniciativas constituíram relevante fonte de financiamento em tempos de recursos escassos e contribuíram para a multiplicação de pesquisas entre os sociólogos rurais. De acordo com Smith, a forma como as "atividades de ajuda federal e bem-estar se desenvolveram nos anos 1930 desempenharam papel muito importante em minha própria identificação, assim como a da maior parte dos sociólogos rurais naquela década, com o campo da Sociologia Rural" (1973: 25).

Marcados por um horizonte reformador convergente com o espírito do New Deal, que se propunha a estabelecer uma nova forma de pactuação social capaz de minorar os excessos do capitalismo liberal e da crise provocada pelas forças do mercado (Patel, 2016), os sociólogos rurais agiram no sentido de indicar que a formulação e a implementação das políticas de Estado deveriam levar em conta as instituições, os valores e as práticas das famílias de agricultores locais Como veremos mais à frente, o estudo dessas pequenas comunidades forneceu elemento importante para a construção da identidade cognitiva da disciplina. 
Os elos estreitos da sociologia rural com a administração de Roosevelt prepararam o terreno para a inserção de profissionais da área no OFAR quando a política de cooperação agrícola interamericana começou a dar os seus primeiros passos. No final dos anos 1930, com a iminência da guerra e sob o impulso do secretário de agricultura Henry Wallace, o órgão se voltou para a elaboração de programas de assistência técnica em agricultura e educação rural para a América Latina (Henningson, 1981). Filho de fazendeiros de classe média do Meio Oeste e economista agrícola de formação, Wallace foi um dos intelectuais-chave na elaboração das políticas do New Deal para as populações rurais, e esteve à frente do Departamento de Agricultura durante os dois primeiros mandatos de Roosevelt - antes de se tornar seu vice-presidente em 1940 (Gilbert, 2015). Grande entusiasta da Política de Boa Vizinhança, Wallace acreditava que a cooperação agrícola constituía um dos pilares da "solidariedade hemisférica". A seu ver, o fortalecimento das trocas comerciais entre as Américas adviria do controle da produção de excedentes agrícolas do hemisfério ocidental que não pudessem ser escoados para os próprios mercados do continente. Também poderiam ser desenvolvidas parcerias econômicas em torno da exploração do potencial produtivo de commodities tropicais de crescente demanda nos EUA em razão da guerra, tais como borracha, abacá e cinchona. Wallace afirmava que o cultivo desses produtos, considerados estratégicos, demandava a cooperação técnico-científica entre os governos da região (Wallace, 1940).

Em setembro de 1941, após expressar insatisfação com o trabalho que vinha sendo realizado pelos adidos agrícolas na América Latina, Wallace propôs que sociólogos rurais fossem enviados a países da região, em missões conjuntas do OFAR e do Departamento de Estado, a fim de coletarem informações mais detalhadas sobre a vida socioeconômica local (Bursley, 1941). Ele conhecia de perto o trabalho que esses profissionais vinham desenvolvendo nos EUA a partir das políticas do New Deal de assistência às populações rurais. Na década de 1930, período em que Wallace esteve à frente do Departamento de Agricultura, a Division of Farm Population and Rural Welfare, unidade que concentrava o trabalho dos sociólogos rurais, havia crescido expressivamente em quadros e recursos (Larson e Zimmerman, 2003: 33-34).

M. L. Wilson, então diretor dos serviços de extensão rural dos EUA e antigo braço direito de Wallace, foi um importante porta-voz da relevância prática das ciências sociais para o trabalho de cooperação com a América Latina. A seu ver, elas poderiam ser úteis nos progra- 
mas de extensão rural que Washington, em parceria com governos locais, planejava iniciar na região a partir da instalação de estações agrícolas experimentais. Igualmente envolvido com o New Deal no plano doméstico, Wilson havia argumentado que a difusão de técnicas agrícolas avançadas pelo interior dos EUA, especialmente no Sul pobre, exigia o conhecimento das formas de organização social e cultura esposadas pelo homem do campo. Em vez de impor medidas à força, as agências precisavam conquistar a adesão dos agricultores a seus programas, o que supunha o reconhecimento de que os valores e as concepções de vida de técnicos e das populações-alvo das políticas não eram necessariamente coincidentes (Wilson, 1940). O caso da América Latina parecia ainda mais complexo para Wilson, uma vez que os EUA careciam de conhecimentos sociológicos e antropológicos acerca das tradições e instituições desses povos, majoritariamente "índios ou descendentes miscigenados de índios", conforme observava em reunião realizada pelo OFAR em Washington, D. C. (Committee on Inter-American, 1940: 44).

Carl Taylor, chefe da Division of Farm Population and Rural Welfare do Departamento de Agricultura, esteve no centro das articulações entre cientistas sociais e agências do Estado que levaram sociólogos rurais a países como Argentina, Brasil e México no início de 1942, em plena guerra. Essas viagens inauguraram o ciclo de estudos e atividades de aconselhamento técnico que desenvolveram na América Latina ${ }^{7}$. A pedido do OFAR e do Departamento de Estado, Taylor ficou responsável por recrutar profissionais da área. A ele foi ainda solicitado que formalizasse em memorando o tipo de atividade que os sociólogos rurais deveriam desempenhar. Conforme confidenciava a T. Lynn Smith, os quadros do corpo diplomático americano "não [sabiam] o que [era] um sociólogo" (Taylor, 1941: 2).

Como indica a versão final do memorando, Taylor conseguiu convencer o Departamento de Estado quanto à pertinência do trabalho dos sociólogos rurais em frentes de ação consideradas de extrema importância para o órgão. Estudar a "organização social no âmbito da agricultura, da produção agrícola e do consumo (incluindo hábitos alimentares)" poderia contribuir para o aconselhamento dos quadros governamentais dos EUA “interessados em problemas socioeconômicos do país [latino-americano] na medida em que estes se relacionem aos problemas mais amplos de cooperação hemisférica" (Christy, 1942: 1). Questão igualmente urgente para os norte-americanos, especialmente depois do ataque a Pearl Harbor, 
dizia respeito à necessidade de avaliar em que medida as colônias de italianos, alemães e japoneses, fixadas em diferentes países da América do Sul, constituíam focos potenciais de hostilidade que tornavam a região vulnerável à invasão pelas forças do Eixo. A esse respeito, Taylor não se valeu de meias palavras ao propor que os sociólogos rurais reunissem informações acerca da composição étnica desses países para analisar "a extensão em que tais grupos foram assimilados à cultura doméstica, e a extensão em que permaneceram como ilhas culturais e, portanto, possivelmente como grupos subversivos na vida nacional" (Christy, 1942: 1). Os sociólogos rurais, por outro lado, buscaram garantir que suas missões para o governo norte-americano viabilizassem a condução de estudos que, dentro das limitações de tempo e recursos que se impunham, tinham o propósito de lançar as bases para a ampliação do conhecimento sobre as populações rurais de diferentes regiões do mundo. Tal objetivo os levou a debater as categorias de análise que deveriam adotar conjuntamente na realização de suas respectivas pesquisas para que seus resultados fossem comparáveis (Taylor, 1942). Seus interesses primaciais incluíam as formas de associação existentes localmente, como as vizinhanças e as comunidades, e o modo como a estrutura fundiária influía sobre a organização social. Nesse sentido, no lugar de terem sido simplesmente instrumentalizados pelos interesses geopolíticos dos EUA, esses estudiosos procuraram se valer da ocasião para fazer avançar sua ciência, igualmente comprometida com uma agenda de reforma social.

Um dos primeiros nomes a ocorrer a Taylor foi o de T. Lynn Smith, que desde o início dos anos 1930 se mostrava interessado no estudo dos povos latino-americanos. Smith era proveniente de uma família de fazendeiros mórmons que haviam se estabelecido, ainda no século XIX, no sul do Colorado, nas proximidades da fronteira com o México. Após concluir o doutorado na Universidade de Minnesota, no Meio Oeste, tornou-se professor da Universidade Estadual da Louisiana em 1931. Seus anos de formação acadêmica foram marcados pela ascendência intelectual de Pitirim Sorokin e Carle Zimmerman, autores de influentes manuais sobre Sociologia Rural nos EUA: Principles of Rural-Urban Sociology (1929) e A Systematic Source Book in Rural Socio$\log y$ (1930), este último em parceria com Charles Galpin. De 1934 a 1938, Smith supervisionou os levantamentos realizados no estado da Louisiana no âmbito da Works Progress Administration (WPA). Entre as atribuições da conhecida agência do New Deal estavam a abertura de postos de trabalho para as massas empobrecidas e a concessão de crédito para pequenos fazendeiros. 
Nos anos de 1935 e 1938, Smith empreendeu incursões ao México. A curiosidade pelo país foi característica de diversos intelectuais do New Deal sensíveis à sorte das camadas rurais pobres dos EUA, especialmente daquelas vivendo nas plantations, que acompanharam com interesse a política fundiária redistributiva que o governo mexicano vinha implementado (Olsson, 2017). Em 1939, Smith realizou visitas de reconhecimento a diversos países da América do Sul com bolsa da Julius Rosenwald Fund, fundação conhecida por financiar projetos de estudo para as populações negras do sul dos EUA. A viagem, que fazia parte dos esforços da Universidade da Louisiana em incrementar o intercâmbio acadêmico interamericano, também serviu para que Smith observasse as práticas de educação rural e os sistemas locais de divisão da terra tendo em vista a realização de futuras pesquisas mais sistemáticas na região. Smith exerceu papel-chave na forma como se estruturaram as missões dos sociólogos rurais na América Latina. Ele foi responsável por indicar, a partir de sua rede de contatos acadêmicos, nomes que atuaram junto ao OFAR, tais como Lowry Nelson e Nathan Whetten ${ }^{8}$. Por recomendação de Smith, Olen Leonard, seu ex-aluno na Universidade de Louisiana, também se envolveu profissionalmente com a agência norte-americana?

As primeiras viagens internacionais dos sociólogos rurais a cargo do OFAR transcorreram em 1942. As missões de Smith (Brasil), Taylor (Argentina) e Whetten (México) envolveram a permanência desses sociólogos nos países em questão, onde atuaram, junto ao corpo diplomático norte-americano, por mais de um ano. A partir de então, o OFAR passou a se valer regularmente do auxílio de cientistas sociais para o planejamento de suas ações na América Latina. Eles foram acionados especialmente para a realização de estudos preliminares sobre as populações-alvo de programas de extensão rural e desenvolvimento agrícola, levados a cabo pelo governo dos EUA e por instituições filantrópicas como a Rockefeller Foundation, em países como Peru, Colômbia, Equador, El Salvador e Costa Rica. Desde o início dos anos 1940, na esteira de sucessivos acordos bilaterais, o OFAR vinha instalando estações agrícolas experimentais em Tingo María (Peru), El Recreo (Nicarágua), Pichilingue (Equador) e Santa Tecla (El Salvador) a fim de levar adiante a política de cooperação agrícola de Henry Wallace (Cuvi, 2011). Tais planos avançaram significativamente em 1942, com a fundação do Inter-American Institute for Cooperation on Agriculture (IICA), nas proximidades da cidade de Turrialba, Costa Rica. Idealizada para funcionar como um centro de experimentação científica em agricultura tropical, a instituição era administrada a partir de Washington e composta por representantes de diferentes nações americanas ${ }^{10}$. 
Os trabalhos de Smith na Colômbia e os de Charles Loomis no Peru, ambos de 1943, haviam convencido os dirigentes do OFAR da pertinência de estudos sociológicos para as políticas de cooperação agrícola ${ }^{11}$. O estudo de Loomis assinalava o papel que os laços comunitários e as lideranças locais dos povoados peruanos poderiam desempenhar na introdução de técnicas avançadas de agricultura ${ }^{12}$. Ele havia conseguido mapear e dispor em diagramas detalhados os canais informais de comunicação, baseados em vínculos vicinais, que poderiam ser utilizados pelos agentes de extensão rural. Os resultados das pesquisas de Loomis receberam a aprovação entusiasmada do agrônomo e especialista em solo Ross E. Moore, diretor-assistente do OFAR, que, em janeiro de 1944, escreveu ao chefe da estação agrícola experimental do Equador, Lee Hines: "A maioria de nós sabe que um dos problemas mais difíceis com que nos defrontamos no desenvolvimento do fornecimento adequado de produtos estratégicos e complementares é aquilo que pode ser denominado o problema humano" (Moore, 1944: 1).

Em outubro de 1943, após as primeiras experiências de pesquisa sociológica, o OFAR iniciou o Foreign Agriculture Rural Sociological Project, no âmbito da então recém-instituída Division of Extension and Training, inicialmente chefiada por Loomis. Elaborado com o auxílio de Carl Taylor, o projeto previa a participação de cientistas sociais no planejamento dos serviços de extensão rural em países latino-americanos, na condução de estudos sobre colonização e povoamento e na coleta de dados relativos à população, organização social, padrões de ocupação e divisão de terras e níveis e padrões de vida nas localidades rurais. Eles deveriam, igualmente, contribuir com a elaboração e com a avaliação dos programas de treinamento instituídos pelo Departamento de Agricultura para a formação de técnicos extensionistas oriundos da América Latina (Estados Unidos, 1943). A partir de 1944, Olen Leonard assumiu a chefia da Division of Extenstion and Training, que em seguida passou às mãos de Glenn Taggart. Em meados dos anos 1940, a unidade promoveu estudos sobre os grupos de localidade, a posse da terra e as atitudes das populações de zonas rurais do Equador, a fim de auxiliar a implantação de serviços de extensão rural e de projetos de colonização no país. Seus quadros também se envolveram com a formulação de programas de educação rural junto aos governos do Peru, Guatemala e El Salvador (Lesser, 1946; Loomis, 1945; Nelson, 1967). 
De acordo com a argumentação dos sociólogos rurais, os planos para a transmissão de práticas modernas de cultivo da terra somente poderiam ser implementados de modo inteligente e eficaz caso fossem precedidos pela inspeção das condições sociais e culturais e da estrutura das comunidades que seriam objeto de intervenção (Moore, 1944). Todavia, conforme indicaremos, na perspectiva desses cientistas sociais, o incremento da produção agrícola na América Latina não constituía um fim em si mesmo, mas se mantinha articulado ao horizonte reformador, de tipo comunitário, característico de sua atuação profissional.

\section{VISÕES SOBRE A AMÉRICA LATINA}

As atividades realizadas pelos sociólogos rurais no âmbito do OFAR deram origem a relatórios e memorandos para o governo norte-americano, a artigos acadêmicos em periódicos como Rural Sociology e Applied Anthropology e a uma série de livros sobre as populações rurais de diferentes países latino-americanos. Inaugurando esse conjunto de obras, Smith publicou, em 1946, o volume Brazil, People and Institutions, à qual se seguiu Rural Life in Argentina (1948), de Carl Taylor; Rural Mexico (1948), de Nathan Whetten; Rural Cuba (1950), de Lowry Nelson; Bolivia, Land, People and Institutions (1952), de Olen Leonard; e Colombia: Social Structure and the Process of Development (1967), de Smith ${ }^{13}$.

Esses livros, que seguiam uma estrutura interna semelhante e exibiam os mesmos interesses investigativos, refletem a unidade de propósitos de seus autores. Por meio deles, é possível vislumbrar a agenda que os sociólogos rurais perseguiram no âmbito das ciências sociais. Tal programa investigativo dificilmente pode ser reduzido aos imperativos práticos e políticos imediatos das agências norte-americanas, como o aumento da produção de materiais estratégicos e a neutralização da influência nazifascista na América Latina no contexto da guerra, ainda que não tenha se mantido completamente alheio a essas preocupações.

A análise de tais obras indica, em realidade, a forte orientação prático-reformadora da sociologia rural que se consolidou durante o New Deal de Roosevelt. Os praticantes da disciplina aspiravam a um mundo rural moderno, que gozasse de elevados padrões de consumo e racionalidade produtiva, mas que fosse ao mesmo tempo organizado em torno da pequena propriedade familiar e de uma vida comunitária e associativa pujante. Esse horizonte normativo se 
evidencia quando se consideram os eixos estruturantes e as questões norteadoras desses estudos: as dimensões geográficas e a estrutura das comunidades rurais ("grupos de localidade"); seus aspectos populacionais e instituições (família, igreja, escola, associações civis, formas de governo local); níveis e padrões de vida; os padrões de ocupação, distribuição, cultivo e posse da terra assim como seus efeitos sociais (a "relação do homem com a terra", no jargão desses sociólogos); e o grau de participação das populações rurais na vida política local e nacional.

Note-se que o tipo de utopia subjacente à abordagem investigativa dos sociólogos rurais não implicava a celebração tout court dos efeitos da modernização e do desenvolvimento tecnológico e econômico, que enxergavam com cautela na medida em que pareciam fomentar o agigantamento de estruturas políticas e econômicas impessoais, como o Estado e o mercado, e colocar em risco os laços de solidariedade locais entre as famílias de agricultores. Essa compreensão da modernização prendia-se a uma matriz comunitarista de pensamento que, ao lado da atmosfera intelectual da Era Roosevelt, contribuiu para que os sociólogos rurais se perguntassem sobre as particularidades do desenvolvimento na América Latina em vez de imaginá-lo como uma marcha inexorável rumo ao padrão societal norte-americano.

Tal matriz comunitarista remontava à própria constituição do campo da sociologia rural nos EUA, que se firmou intelectualmente em oposição à crença de que o fazendeiro possuía uma existência atomizada. Com efeito, pode-se dizer que a disciplina nasceu sob o signo da comunidade (Brunner, 1957; Nelson, 1969; Smith, 1974). Afinal, o esforço de legitimação de sua validade enquanto ciência envolvia a comprovação da existência dos pequenos grupos enquanto entidades sociais reais, e não imaginadas, do mundo rural. Havendo um objeto específico a ser estudado, um domínio da natureza com existência própria, a razão de ser da disciplina estava justificada. Não à toa, Charles Galpin mereceu o título de founding father da sociologia rural. Primeiro diretor da Division of Farm Population and Rural Life, cargo que ocupou de 1919 a 1934, Galpin divisou estratégias para delimitar os contornos físico-espaciais das comunidades rurais do Meio Oeste dos EUA a partir do mapeamento dos "emaranhados de vida humana" que surgiam das visitas e frequências das famílias de agricultores, aparentemente isoladas, a instituições como a escola, a igreja e estabelecimentos comerciais das proximidades (Galpin, 1915: 18). 
O comunitarismo que informou a leitura dos sociólogos rurais sobre a realidade social se fundava na crença acerca da existência da comunidade não apenas como tipo de agrupamento humano efetivamente existente, mas como forma superior de ordenamento das relações, orientada pelos princípios de coesão, solidariedade, consenso e ação conjunta para fins comuns ${ }^{14}$. A conclusão prático-política que se inferia da ênfase desses cientistas sociais sobre a comunidade apontava para a necessidade de os planos de intervenção sobre as condições de vida das populações rurais considerarem os "grupos naturais" ou "formas naturais" de associação das localidades, assim como seus costumes e crenças, sem os quais nenhuma política pública poderia vingar.

Durante o New Deal, tal expediente argumentativo se tornou comum entre os sociólogos rurais para justificar a relevância de seu trabalho junto às agências governamentais. Em um período no qual o planejamento e as políticas do governo federal ganhavam magnitude, era preciso exorcizar o fantasma do "totalitarismo" e dos "planos quinquenais" e garantir que as comunidades participassem da implementação e da avaliação das políticas de controle da produção agrícola delineadas pelo corpo burocrático de Washington. Essa ideia foi consubstanciada no Cooperative Land-Use Program, lançado pelo Bureau of Agricultural Economics, do Departamento de Agricultura, em fins dos anos 1930. Nesse programa, os sociólogos rurais tiveram papel destacado, atuando junto às populações na delimitação das "comunidades naturais" existentes nas zonas rurais de modo a garantir que estas estivessem representadas nos comitês locais responsáveis por elaborar os planos de ação (Gilbert, 2015).

Com seu enfoque característico sobre a comunidade, os sociólogos rurais estiveram envolvidos em políticas governamentais que visavam atacar o problema da pobreza no campo a partir de programas de saúde, educação, assistência social, crédito rural a trabalhadores e rendeiros para aquisição de terras, reassentamento de agricultores e organização de cooperativas. Participaram, ademais, do planejamento de comunidades modelos em áreas limítrofes dos centros urbanos (Immerwarh, 2015; Kirkendall, 1966). Eles não apenas propunham que a implementação das políticas se apoiasse na capacidade de cooperação e mobilização das populações rurais, como também procuravam garantir que os planos de intervenção fortalecessem a vida comunitária das vilas e condados. Essa preocupação fez com que se perguntassem sobre os padrões de distribuição espacial dos lotes de terra e os tamanhos das fazendas mais favoráveis à integração dos grupos em nível local (Loomis, 1939; Smith, 1935). 
Ainda que a imaginação comunitarista dos sociólogos rurais tenha sido estimulada pelos projetos de engenharia social de Roosevelt em face da Grande Depressão, eles manifestavam apreensões de fundo quanto às ameaças que a modernização capitalista no campo representava para o potencial comunitário de suas populações. As forças da modernidade pareciam agir no sentido da atomização social, agudizando a competição econômica, e da proletarização das massas rurais, especialmente nas áreas das grandes plantações, como as do Sul profundo. Tais processos apontavam para a divisão e o conflito sociais, e não para o mundo coeso de comunidades de famílias fazendeiras de classe média que constituía o horizonte dessa sociologia.

Foi com essas questões em mente que os sociólogos rurais voltaram seu olhar para a América Latina: procurando por sinais que indicassem ser possível conciliar a mecanização da agricultura com a construção de robusta vida associativa local no campo. Assim, em que pesem as lacunas e deficiências que identificavam, como as técnicas produtivas rudimentares e a estrutura fundiária concentracionista, eles avaliavam, a partir de imagens por vezes bastante idealizadas da região, que seu progresso técnico e material poderia transcorrer segundo linhas comunitárias. A aposta dos cientistas sociais era a de que os povos latino-americanos contornassem o individualismo exacerbado característico do fazendeiro médio dos EUA, envolvido com uma agricultura de tipo comercial (cash crop) e orientado quase exclusivamente pela busca do lucro ${ }^{15}$.

Os pressupostos que orientavam o olhar dos sociólogos rurais para a América Latina eram compartilhados por diferentes círculos intelectuais e acadêmicos nos EUA. A partir dos anos 1920 e 1930, com os primeiros sinais de crise do capitalismo liberal, intelectuais insatisfeitos com o excessivo individualismo e materialismo da sociedade norte-americana passaram a enxergar os vizinhos do sul como parte de uma outra América: mais próxima de formas de vida comunitárias e ainda não inteiramente tocadas pelas mazelas da civilização urbano-industrial. Vistas tradicionalmente pelos EUA como lugar do primitivismo e da degeneração provocada pela intensa miscigenação racial, as sociedades latino-americanas adquiriram coloração positiva nas lentes dos setores reformadores da Era Roosevelt, sendo consideradas fonte potenciais para a construção, em bases renovadas, de uma cultura moderna e inter-americana ${ }^{16}$. 
Nas ciências sociais, novos olhares para a América Latina não estiveram dissociados de processos em curso de revisão das antigas concepções evolucionistas, e da construção de perspectivas mais nuançadas sobre as implicações da modernidade para os agrupamentos humanos (Pike, 1985). Nas reflexões de Park sobre a cidade, por exemplo, fundantes da tradição sociológica de Chicago, havia certa ambiguidade na avaliação dos efeitos das aceleradas mudanças sociais típicas do contexto urbano-industrial. Por um lado, as formas impessoais de relação das metrópoles modernas e a participação do indivíduo em um número diversificado de círculos permitiam a expansão da personalidade e o desenvolvimento de suas faculdades. Por outro, o anonimato apontava para a substituição dos "contatos primários" pelos "secundários", gerando o enfraquecimento da ordem moral e da cooperação vistas como típicas da vida em comunidade. Segundo Park, esse processo estaria na origem da "desorganização social", visível em fenômenos como o divórcio, a criminalidade urbana, a delinquência juvenil, a loucura e os conflitos raciais (Park e Burgess, 1967 [1925]; Smith, 1988).

Essa ambiguidade acerca das consequências benfazejas da modernidade acompanhou conhecidas pesquisas realizadas por alunos de Park na América Latina. Esse foi o caso do estudo de Robert Redfield no povoado rural mexicano de Tepoztlán, conduzido em fins dos anos 1920. Embora considerasse como irreversíveis as transformações que se operavam localmente sob a influência dos centros urbanos (em especial a secularização, a individualização e a desorganização social), o trabalho de Redfield era atravessado por um sentimento nostálgico em relação à "cultura de folk". À diferença da cultura de massas, aquela seria característica de tradições locais que, embora presas a uma compreensão mágica do mundo, eram capazes de dotar de significado a existência dos indivíduos (Wilcox, 2006). Ademais, em contraste com a civilização urbano-industrial, a vida social dos tepoztecos parecia marcada por estreitos laços de solidariedade interfamiliar e vicinal, formando um tipo de associação em que a obrigação moral para com o grupo prevalecia sobre os interesses individuais (Redfield, 1930).

O México estava entre os países que mais despertavam a curiosidade dos círculos reformadores agrários do New Deal, nos quais os sociólogos rurais se incluíam. Ideais de partilha da terra que haviam insuflado a Revolução Mexicana e que vinham sendo experimentadas em pequena escala, como os ejidos, haviam capturado a imaginação de intelectuais como Frank Tannenbaum e Henry Wallace (Olsson, 2017) ${ }^{17}$. 
Os sociólogos rurais pareciam partilhar do otimismo de Wallace quanto à possibilidade de aumento da produção agrícola na América Latina com base em empreendimentos de tipo cooperativo (Pike, 1985). Escrevendo sobre o México, Whetten afirmava que a multiplicação dos ejidos havia contribuído para a quebra do monopólio da terra e para uma maior distribuição dos seus rendimentos - ainda que as populações rurais seguissem carentes de técnicas agrícolas eficientes e apresentassem baixos níveis de vida (Whetten, 1948). Na Argentina, conforme ponderava Taylor, os novos projetos de colonização, centrados em fazendas familiares, vinham dando origem a comunidades coesas. Em vivo contraste com a intrincada estrutura dos grupos rurais nos EUA, a integração social se operava a despeito das diferentes origens étnicas e nacionais dos agricultores (Taylor, 1944). Tal aposta na comunidade foi marca característica do diagnóstico sociológico de Smith sobre a vida nas zonas rurais brasileiras.

\section{O BRASIL PROFUNDO DE T. LYNN SMITH E A UTOPIA COMUNITÁRIA}

A análise de Smith sobre o Brasil rural é particularmente reveladora das diferentes leituras que os norte-americanos realizaram sobre as mudanças modernizadoras em curso entre os povos latinos, nem sempre vistas como conduzindo fatalmente ao tipo de civilização urbano-industrial prevalecente nos EUA. Ela lança luz, ademais, sobre o papel que tradições de conhecimento da intelectualidade local desempenharam nas pesquisas sobre a região empreendidas por cientistas sociais provenientes do Atlântico Norte ${ }^{18}$. Embora não inteiramente examinada pela literatura, tal dimensão da produção sociológica do passado sugere que, para além de um fluxo unilateral de ideias, diálogos intelectuais transnacionais ajudaram a moldar obras e estudos gestados tanto no Sul quanto no Norte ${ }^{19}$.

Smith chegou ao Brasil em fevereiro de 1942 e permaneceu no país até janeiro do ano seguinte, na qualidade de analista agrícola sênior associado ao adido agrícola Erwin Keeler, da embaixada norte-americana no Rio de Janeiro. Durante esse tempo, o sociólogo realizou incursões a diversos estados brasileiros ${ }^{20}$. Smith não se limitou a visitar as capitais, adentrando também os distritos rurais. Nessas viagens, além de observações de campo, realizou o levantamento de dados oficiais de órgãos das administrações estaduais e locais voltados para as áreas de educação, estatística, agricultura, terras e 
colonização. Serviu-se, também, de informações de agências como o Instituto Nacional de Estudos Pedagógicos e o Instituto Brasileiro de Geografia e Estatística (Smith, 1942).

Nesse período, valendo-se da política de aproximação cultural dos EUA, Smith procurou estreitar os laços com intelectuais brasileiros, como o antropólogo Arthur Ramos, da Faculdade Nacional de Filosofia, a fim de estabelecer canais regulares de troca e cooperação com o mundo acadêmico das ciências sociais em construção no Brasil. Como parte desses esforços, ministrou um curso de "Métodos e técnicas de pesquisa em análise populacional e sociologia da vida rural" na Escola Livre de Sociologia e Política de São Paulo (atual FESPSP). Fruto de acordo entre a embaixada norte-americana e o governo de São Paulo, o curso foi implementado com o auxílio do sociólogo Donald Pierson (Pierson, 1942). No pós-Segunda Guerra, Smith orientou os estudos pós-graduados dos brasileiros José Arthur Rios e José de Freitas Marcondes na Universidade Estadual da Louisiana. Ele ainda manteve vínculos com cientistas sociais como Emílio Willems, em São Paulo, e Antônio Carneiro Leão, no Rio de Janeiro, convidados para ministrar cursos nos EUA (Lopes, 2020).

A circulação de Smith pelo território brasileiro, assim como a cooperação que obteve de funcionários do governo brasileiro (Smith, 1946), somente se tornam inteligíveis ao se considerar o alinhamento do Brasil aos EUA durante a Segunda Guerra Mundial, posição que foi consolidada ao longo do ano de 1942. Um dos marcos na construção dessa aliança foi o processo de negociação entre Vargas e Roosevelt na Conferência dos Ministros das Relações Exteriores, realizada no início daquele ano, no Rio de Janeiro. Os entendimentos entre os dois governos levaram ao rompimento das relações do Brasil com o Eixo e a uma série de acordos bilaterais que estipulavam o provimento de equipamento militar e industrial ao país pelos EUA, em troca da exclusividade norte-americana na compra de excedentes de produtos primários estratégicos para a guerra (Moura, 2012).

Os pontos principais que constituíram a missão que o governo norte-americano confiara a Smith transparecem em suas anotações de viagem. No interior de São Paulo, além de tomar nota de grandes fazendas dedicadas à produção de algodão, açúcar e café (commodities importantes no comércio exterior), ele registrou a presença "conspícua" de japoneses nas proximidades de localidades rurais 
como Marília (Smith, 1942b: 28). Em setembro de 1942, com base em informações do censo e de agências de imigração, enviou ao Departamento de Estado um relatório estimando o número total de japoneses e seus descendentes em São Paulo e a distribuição espacial de suas colônias no interior do estado (Smith, 1942c). No Sul do Brasil, seus passos o levaram em direção a cidades de colonização alemã, como Blumenau (Smith, 1942a). Em Londrina, pôs-se a par dos planos de colonização da Companhia de Terras do Norte do Paraná (Smith, 1942b). Na extremidade norte do país, em pequenas localidades do Maranhão, Smith observou a atividade dos coletores de sementes de babaçu, rica fonte de óleo vegetal. $\mathrm{O}$ aumento da demanda ocasionado pela guerra havia levado os agricultores locais a abandonarem o cultivo de produtos alimentícios básicos, gerando uma crise de abastecimento interno. No Pará, percorreu os municípios de Bragança e Santa Isabel, detendo-se em pequenas pensões ao longo do caminho a fim de investigar as razões do baixo número de trabalhadores migrantes do Nordeste que chegavam às zonas de extração da borracha na Amazônia (Smith, 1942a). Essas viagens foram realizadas na companhia do antropólogo Charles Wagley, da Universidade de Columbia, que desde 1939 estudava grupos indígenas em cooperação com o Museu Nacional. No início dos anos 1940, como parte dos esforços de guerra, Wagley atuou no Serviço Especial de Saúde Pública, órgão criado a partir de acordo bilateral entre os governos brasileiro e norte-americano. A partir desta agência, ele contribuiu com os programas de educação sanitária e assistência médica destinados às populações sertanejas recrutadas para o trabalho nos seringais (Campos, 2006; Figueiredo, 2009; Maio, 2019).

Ao final de seus deslocamentos, Smith produziu um relatório sobre a força de trabalho brasileira empregada em atividades agropecuárias e extrativistas. Debruçou-se, como sociólogo, sobre a variável ou fator humano que deveria ser levada em conta nos planos de cooperação interamericana destinados ao incremento da produção de materiais estratégicos no país (Smith, 1943a). Em meados de 1943, já de volta aos EUA, redigiu seu relatório final (1943b). O texto abrangia diferentes aspectos da população e da vida social brasileira, tais como: taxas de mortalidade, fertilidade e crescimento; distribuição da população pelo território; imigração e migrações internas; níveis e padrões de vida; formas de ocupação da terra; distribuição e tamanho da propriedade fundiária; e estrutura dos grupos de localidade. O documento serviu 
de base para a publicação, três anos depois, do livro Brazil: People and Institutions (1946) - extenso volume cuja primeira edição possui 843 páginas entremeadas por mapas, gráficos e fotografias.

No esforço de tornar inteligível a situação do trabalho e da produtividade no Brasil rural, Smith recorreu a uma compreensão da história social do país que é devedora, sobretudo, dos marcos interpretativos estabelecidos por Francisco José de Oliveira Vianna (1938). Nascido em uma família de fazendeiros do interior do Rio de Janeiro e formado em Direito, Oliveira Vianna atuou como consultor do Ministério do Trabalho durante o Primeiro Governo Vargas. Sua obra, conhecida pelas críticas de que o ordenamento jurídico-político liberal instituído pela Primeira República estaria em descompasso com a realidade social brasileira mais profunda, acabou sendo identificada como das fontes de sustentação ideológica do regime de 1937. Em sua leitura do Brasil, o escritor apontava para a heterogeneidade sociocultural, regional e étnica do país e para a ausência de formas de solidariedade social fora do âmbito familiar. Esses elementos seriam capazes de conferir vertebração ao povo e às instituições do autogoverno. Diante da amorfia reinante, o autor de Populações Meridionais do Brasil prescrevia a ação virtuosa de um Estado forte e centralizador na organização da sociedade e na construção da ordem pública.

A visão hierarquizante presente nos textos de Oliveira Vianna, evidente em sua adesão ao racialismo e no encaminhamento político autoritário para o problema do particularismo familista e desagregador, contrastam com as premissas igualitárias e participativistas da sociologia rural de Smith. Ainda assim, a obra do escritor fluminense assumiu centralidade na leitura que o norte-americano desenvolveu a respeito do Brasil. Esse é o caso, especialmente, de suas considerações acerca da prevalência de uma estrutura fundiária concentracionista na ocupação do território e do efeito simplificador do latifúndio sobre a formação da sociedade brasileira, que seria uma das raízes do seu insolidarismo ${ }^{21}$.

Ao se voltar para a história, Smith recorreu à ideia, presente em Populações Meridionais do Brasil, de que a colonização do território brasileiro, a partir da grande propriedade rural, havia representado uma ruptura com a tradição portuguesa da pequena propriedade; o que acabou sendo decisivo para a forma como a cultura e a sociedade brasileira se estruturaram (Smith, 1943b). Tal havia sido o poder modelador da grande propriedade rural na história do país, que ela estava na origem 
da forma rotineira e simplificada com que a agricultura era praticada, com excessivo uso de mão-de-obra em detrimento do investimento em tecnologia. Esse padrão era observado tanto nas monoculturas exportadoras quanto na pequena agricultura de subsistência (Smith, 1943a). As práticas de cultivo prevalecentes entre os camponeses portugueses haviam, no processo de ocupação do território brasileiro, cedido ao hábito indígena das queimadas na preparação da terra para o plantio. Conjugado ao forte e generalizado estigma que pesava sobre o trabalho braçal, herança de séculos de escravidão, o latifúndio estava na raiz de uma estrutura social rudimentar. Enquanto uma massa de trabalhadores rurais, sem-terra e itinerantes vegetava na base da pirâmide, seu ápice era ocupado por elites proprietárias de fazendas avessas às tarefas manuais. Não havia espaço para uma classe média de pequenos fazendeiros progressistas dispostos a incrementar sua atividade produtiva em busca de níveis de vida mais elevados e a romper com a inércia do caboclo e com os arcaísmos do latifúndio (Smith, 1943a).

A forma de povoamento, centrada na grande propriedade rural, também havia resultado em uma distribuição dispersiva e isolacionista da população pelo território. $\mathrm{O}$ fenômeno estava na origem da constituição de grupos de localidade (vizinhanças e comunidades) marcados por fracos laços de solidariedade para além da família. Em sua avaliação da comunidade rural no Brasil, Smith foi impactado pela tese do insolidarismo, cuja elaboração clássica coube a Oliveira Vianna (1938). Segundo este último argumentava, haveria uma "carência de instituições de solidariedade social em nosso povo"; isto é, de formas de associação ou "ação em conjunto" visando interesses ou utilidades comuns, como as tradições de cooperação vicinal e os conselhos comunais (Oliveira Vianna, 1938: 205). Para o autor de Populações Meridionais do Brasil, a amorfia da sociedade resultava do predomínio histórico do grande domínio rural, com sua independência socioeconômica, no processo de colonização do país. Esse padrão de ocupação havia ensejado círculos de solidariedade restritos aos clãs e às famílias, constituindo a "única forma de solidariedade social que realmente sentimos, [...] única que realmente praticamos" (Oliveira Vianna, 1938: 205).

Como indicado, tal era a relevância do objeto "comunidade" para a constituição de um domínio próprio de estudos para a sociologia rural nos EUA, que os praticantes da disciplina se empenharam em demonstrar sua existência enquanto grupamento empiricamente observável. Por essa razão, no lugar de simplesmente constatar a ausência de amplos laços 
de solidariedade social no Brasil, Smith empreende uma análise que se apoia, sobretudo, em projeções quanto ao futuro das formas associativas das localidades rurais do país. Ou seja, ainda que o sociólogo enxergue as formas de solidariedade como marcadas pelo familismo, sua aposta recai sobre a capacidade de expansão comunitária desses vínculos.

Smith afirma que, em se tratando do desenvolvimento de suas comunidades, as zonas rurais brasileiras estavam mais atrasadas do que os estados sulistas dos EUA, permanecendo em um "estado amorfo" (Smith, 1943b: 101). O sociólogo enxerga no "clã" de Oliveira Vianna um "grupo de vizinhança" - categoria dos sociólogos rurais que indicava uma unidade social anterior à comunidade na evolução das formas associativas, na qual prevaleceriam o contato face a face e práticas de ajuda mútua. Smith nota que no Brasil esses grupos eram, em grande medida, formados por famílias que orbitavam os domínios de um fazendeiro. Embora não se detenha no exame da natureza dos vínculos interpessoais constitutivos desses grupos, o sociólogo não deixa de notar seu caráter assimétrico: "[Nas] pequenas localidades, grandemente distanciadas uma da outra, vive um pequeno grupo de famílias - as do proprietário, seus parentes, e um número variado de empregados, agregados, camaradas, moradores e parceiros" (Smith, 1943b: 100).

Smith indica ainda a existência de "grupos de vizinhança" formados por famílias de "'intrusos', sitiantes e outras classes do povo, que não sofreram a influência e o controle de um fazendeiro; isto é, não se transformaram em seus camaradas e agregados", vivendo nas encostas de serras, em casas de taipa ao longo do litoral, às margens dos rios ou em pequenas clareiras nas florestas (Smith, 1943b: 99). Todavia, considerando-se o insulamento físico, o horizonte social estreito e o exíguo número de relações que mantinham, circunscritos à área de sua residência, esses grupos não chegavam a constituir comunidades na avaliação do sociólogo (Smith, 1943b).

Afinado com as observações de Oliveira Vianna sobre o peso da solidariedade clânica e parental na história social do Brasil, Smith conclui que os vínculos familiares e vicinais absorviam a quase a totalidade das preocupações dos indivíduos, restando muito pouco para o desenvolvimento de atividades em "áreas maiores e mais completas de interação social, tal como a comunidade" (Smith, 1943b: 99). Além do familismo, do isolamento geográfico e da autossuficiência econômica do latifúndio, o predomínio da agricultura de subsistência entre as camadas pobres, a 
baixa escolaridade dos habitantes e a rígida estrutura de classes dificultavam o estabelecimento de relações mais regulares entre as populações locais e os centros das vilas e pequenas cidades - integração que estaria na base de comunidades rurais robustas.

Na visão de Smith, em grande parte informada pela crença no espírito anti-individualista dos povos latino-americanos, longe de ser crônico, esse quadro de insolidarismo tendia a ceder lugar a associações coletivas mais frequentes, fora dos locais de residência das famílias, e a engendrar formas sociais propriamente comunitárias. Esse processo era favorecido pelo estreitamento das relações entre os pequenos centros representados pelas sedes municipais e as populações dos arredores que ocorria sob o influxo do desenvolvimento dos meios de comunicação e transporte.

Repetindo as observações de Galpin, relativas aos fazendeiros norte-americanos, Smith afirmava que o homem rural brasileiro não era "um homem sem comunidade", ainda que os contornos geográficos deste tipo de grupo local ainda não estivessem completamente delimitados no presente e sua constituição plena se apresentasse apenas como uma tendência (Smith, 1943b: 90). Assim como vinha ocorrendo nos EUA, a modernização representada pela quebra do isolamento rural constituía uma mudança bem-vinda, uma vez que ampliava os horizontes sociais dos agricultores e acenava com a promessa de elevação do seu patamar de consumo e bem-estar. Entretanto, de acordo com Smith, à diferença do que havia ocorrido com a sociedade norte-americana, as comunidades rurais brasileiras em formação não pareciam correr o risco da fragmentação e da pulverização decorrentes do individualismo atomizador que irradiava das grandes cidades e que punha em xeque as formas locais de solidariedade. Em seus textos sobre o Brasil, não se encontram indicações equivalentes à preocupação que expressava quanto à necessidade de redefinir e fortalecer o papel econômico desempenhado pelas vilas e aldeias dos EUA, centros de vida comunitária que os sociólogos rurais julgavam ameaçados pela crescente urbanização e da industrialização do país (Smith, 1941; Smith, 1943b).

Em realidade, aos olhos de Smith, o Brasil poderia vir a realizar a utopia comunitarista de Galpin relativo às "comunidades rurbanas": áreas de interação social de fisionomia bem-marcada, formadas a partir da integração das populações das fazendas a um único centro (sede municipal) para o qual convergiriam idealmente as funções políticas, religiosas, sociais e comerciais da localidade. Apesar de serem 
dotadas da infraestrutura e das técnicas avançadas típicas do mundo urbano-industrial, as comunidades rurbanas, no ideário da sociologia rural, conseguiriam manter sua coesão interna, exibindo seus membros capacidade de cooperação para fins comuns. Essas comunidades se diferenciavam daquilo que parecia ser a tendência estadunidense, na qual as famílias de fazendeiros estabeleciam tipos distintos de vínculo (comerciais, recreativos, religiosos, educacionais) com diversas vilas e cidades. Tal processo resultava na distribuição fragmentada dos laços de solidariedade pelo território, não havendo coincidência entre o local de residência do homem do campo e as áreas em que este podia participar da vida política, cultural e econômica do país (Smith, 1943b).

O potencial comunitário do Brasil resultava, na perspectiva de Smith, de determinadas características da sociedade e da cultura do país. Enquanto a legislação dos EUA permitia que as pequenas cidades do interior adquirissem autonomia, desvinculando-se das áreas rurais circunvizinhas (separate incorporation), os municípios brasileiros, seguindo padrão mais centralizador, abrangiam necessariamente, e por força da lei, tanto as vilas que lhes serviam de sede como os distritos e as zonas rurais sob sua influência. Isso tornava o município a unidade político-administrativa ideal em torno da qual a comunidade rural poderia crescer e fixar seus limites. Da mesma forma, a relativa homogeneidade religiosa do país, marcado pela forte ascendência da Igreja Católica, e a ausência de fortes clivagens segundo linhas de cor no interior das vizinhanças contribuíam para tornar menos intrincada a estrutura das comunidades brasileiras emergentes em comparação com as norte-americanas. Essa menor segmentação favorecia a vida comunitária (Smith, 1943b).

Embora Smith não o afirme, sua avaliação positiva dos fatores que seriam favoráveis à integração comunitária no Brasil estava em sintonia com tradições locais de pensamento. Preocupadas com a construção da nacionalidade a partir de populações e regiões consideradas heterogêneas, essas correntes enfatizavam a necessidade de políticas integradoras a partir do alto, do Estado, em nítido contraste com os valores do liberalismo individualista norte-americano. Com efeito, o que Smith registra como traços da sociedade e da cultura brasileira (suas tendências integracionistas) havia sido produto de ideais políticos de nation-building. $\mathrm{O}$ fato de o sociólogo rural ter sido capaz de valorar positivamente esses elementos indica que, para além das conhecidas diferenças na cultura política dos dois países, havia pontos 
de contato entre as vertentes estatizantes do pensamento brasileiro do período (tais como expressas no trabalho de Oliveira Vianna) e os esforços de revisão do laissez-faire operados pelos intelectuais reformadores da Era Roosevelt. Como se sabe, o New Deal havia conferido relevo inaudito às possibilidades de o Estado intervir na sociedade, inaugurando o período dos experimentos em planejamento governamental e engenharia social nos $\mathrm{EUA}^{22}$. No caso de Oliveira Vianna, suas teses partiam de um horizonte político-moral ibérico e católico que era convergente com o comunitarismo da sociologia rural, cuja concepção do mundo social tendia a valorizar os elementos de ordem e consenso em detrimento da dimensão do conflito (Carvalho, 1993; Werneck Vianna, 1997).

Não obstante essas afinidades, o influxo das teses de Oliveira Vianna sobre a forma como Smith retratou o Brasil gerou tensões que se manifestaram em algumas das recomendações práticas do sociólogo rural a respeito de políticas de desenvolvimento rural para o país no pós-Segunda Guerra. No centro de suas considerações estava um programa de reforma agrária fundado na pequena propriedade familiar. Esses planos, que visavam formar uma classe média rural no país, deveriam estar articulados a políticas de educação e saúde apoiadas nos esforços organizativos das próprias comunidades. Taxando o latifúndio improdutivo, os habitantes dos municípios brasileiros conseguiriam não apenas desestimular a retenção de vastas porções de terra para fins especulativos como também obteriam os recursos necessários à manutenção dos serviços básicos de educação, saúde e proteção social em nível local (Smith, 1952). No entanto, em razão do domínio que os grandes fazendeiros pareciam exercer na vida política e administrativa de diversas áreas do Brasil profundo, Smith se viu obrigado a relativizar o papel que as populações locais poderiam desempenhar na implementação dessas políticas. Essas ponderações o levaram a defender, à maneira de Oliveira Vianna, a necessidade de intervenção governamental externa nos casos em que o particularismo, imiscuindo-se no autogoverno, impedisse a conduta republicana na administração dos recursos (Smith, 1952).

As tensões experimentadas pelo comunitarismo de Smith, ao entrar em contato com matrizes autoritárias de pensamento que buscavam tornar inteligível a realidade social brasileira, também se fez presente na atuação de sociólogos que, afinados com sua agenda reformadora, voltaram-se para o desenvolvimento de uma ciência social aplicada 
para os programas de desenvolvimento regional em curso no interior do país nos anos 1950. Esse foi o caso de José Arthur Rios, ex-aluno de Smith que, naquele período, procurou conferir vertebração às comunidades do sertão brasileiro a partir de ações em educação rural e saúde pública a cargo de agências governamentais, tais como a Campanha Nacional de Educação Rural e o Serviço Especial de Saúde Pública. O comunitarismo sobressaía nas estratégias de educação de base e "organização de comunidades" propostas por Rios para a implementação daquelas políticas. Embora o sociólogo nutrisse expectativas acerca da dinamização dos grupos e de sua participação social no processo de mudança em nível local, apreciações desanimadoras da paisagem rural brasileira também faziam parte do seu diagnóstico, que se tornava por vezes ambivalente. Aos olhos de Rios, grande parte do Brasil rural parecia ainda marcado pela hipertrofia da influência familiar e, principalmente, pelas fraturas de classe, fundadas na concentração fundiária, que impediam o estabelecimento de formas comunitárias de cooperação para além dos grupos privados (Lopes e Maio, 2017).

\section{CONSIDERAÇÕES FINAIS}

Os diagnósticos que os sociólogos rurais norte-americanos produziram sobre a América Latina nos anos 1940 convidam-nos a repensar e a matizar as compreensões tradicionais acerca das ideias de desenvolvimento que circularam entre as Américas. Longe de terem aderido sem reservas e de modo triunfalista à ideia de que a modernização capitalista da vida rural redundaria automaticamente em bem-estar social, aqueles cientistas sociais apontaram para os entraves que a urbanização e a industrialização, associadas ao individualismo moderno, haviam criado para o estabelecimento de laços de solidariedade social em nível local. Nesse sentido, o mundo rural latino-americano foi concebido como fonte de experiências societais originais que apontavam para caminhos alternativos à sociedade atomizada, cindida e competitiva característica dos EUA.

A análise do trabalho dos sociólogos rurais indica que nem todas as visões produzidas por norte-americanos a respeito de seus vizinhos ao Sul do continente fundavam-se na percepção de uma grande convergência dos povos em torno do modelo civilizacional urbano-industrial que os EUA representavam. Significativo a esse respeito foi o diagnóstico de Smith sobre o Brasil rural, país que, a seu juízo, dava sinais de ser capaz de se aproximar da utopia comunitária da sociologia 
rural norte-americana. Por fim, os textos de Smith sobre o país e sua aproximação de leituras específicas sobre a realidade social brasileira, como as de Oliveira Vianna, lembram-nos que, para além do jogo de influências e apropriações recíprocas, a produção sociológica do passado foi marcada por afinidades e convergências político-intelectuais entre o Norte e o Sul do globo.

(Recebido para publicação em 3 de fevereiro de 2020)

(Reapresentado em 21 de novembro de 2020)

(Aprovado para publicação em 14 de janeiro de 2021)

\section{NOTAS}

1. Estudos conhecidos sobre os pressupostos político-ideológicos e as raízes históricas da ideia de desenvolvimento encontram-se em Rist (1997) e Escobar (2007). Nas ciências sociais, essa visão teleológica marcou a teoria da modernização de matriz parsoniana, que ganhou o mundo no pós-Segunda Guerra. Cf. Berger (1995); Latham (2000 e 2011); Gilman (2003); Engerman; Gilman; Haefele; Latham (2003).

2. As nítidas vinculações da sociologia rural com uma agenda reformadora e com uma abordagem prática relativa ao problema da mudança social, ajudam-nos a relativizar algumas das críticas que tradicionalmente foram dirigidas às pesquisas que se voltavam para o estudo das comunidades rurais do país como excessivamente acadêmicas ou inócuas para uma compreensão das macroestruturas da sociedade brasileira. Sobre os sentidos assumidos pelos "estudos de comunidade" no Brasil, sua fortuna crítica e os debates teóricos que desencadearam, cf.: Oliveira (2010); Maio et al. (2013).

3. Em 1940, após viagem de reconhecimento pela América do Sul como representante da Louisiana State University, Smith afirmava que professores e alunos constituíam, mais do que industriais, negociantes e viajantes ocasionais, os agentes ideais para a promoção do entendimento entre os países, dada a disposição que teriam para compreender, sem pré-julgamentos ou considerações estritas de ganho econômico, os costumes, as realizações e os problemas de outros povos (Smith, 1940a).

4. Um sucinto histórico do interesse do Departamento de Agricultura dos EUA em desenvolver estudos no exterior foi elaborado por Leslie Wheeler, seu diretor no início dos anos 1940. Cf.: Wheeler (s/d); Hemmingson (1981).

5. Para os quadros do ISA, a questão de uma ciência social "aplicada" somente se tornou saliente no pós-Segunda Guerra. Em esforço para adquirir sobrevida em um momento em que as relações culturais com a América Latina deixavam de ser prioritárias nos planos de Washington, o ISA imprimiu uma reorientação de sua agenda de cooperação científica com a região de modo a torná-la mais afinada com os programas de desenvolvimento regional lançados pelo Governo Truman. O novo horizonte posto para os cientistas sociais da instituição, de uma antropologia a serviço da "mudança cultural" - expressão que traduzia, na linguagem das ciências sociais, a condição necessária para a realização da meta do desenvolvimento econômico e da modernização dos países latino-americanos - desencadeou o debate em torno das relações entre ciência e política, 
ciência "básica" e "aplicada", e tentativas de articulação entre os diferentes compromissos em jogo, percebidos, por vezes, como incongruentes. Cf.: Figueiredo (2009); Maio et al. (2013). Para uma análise crítica, em perspectiva histórica, das relações entre "ciência pura" e "aplicada", conferir: Kreimer e Zabala (2006); Shapin (2008).

6. Os land-grant colleges foram instituições estaduais fundadas no século XIX, com o incentivo da União, a fim de complementar a oferta do ensino clássico com o provimento de formação superior em áreas técnicas como agronomia e engenharia. Intimamente a eles associadas, desenvolveram-se as estações experimentais, que se destinavam ao aprimoramento científico das técnicas agrícolas, e os serviços de extensão rural, responsáveis por difundir esses incrementos técnico-científicos para as populações fazendeiras (Nelson, 1969).

7. Oriundo de uma família de fazendeiros de classe média de Iowa, no cinturão do milho, Carl Cleveland Taylor (1884-1975) atuou inicialmente como ministro protestante antes de ingressar na universidade. Nos anos 1920, quando professor do North Carolina State College, realizou pesquisas sobre os níveis de vida dos trabalhadores rurais e meeiros das plantations sulistas. Durante o New Deal, Taylor, simpático ao movimento pela reforma das condições de vida dos pequenos agricultores, atuou como diretor da Division of Subsistence Homesteads do Department of Interior (1933-34), diretor regional da Seção de Política de Terras da Agricultural Adjustment Administration (1934-35) e diretor assistente da Resettlement Administration (1935-37). Ver Gilbert (2015).

8. Nelson foi professor de Smith na Universidade de Brigham Young (Provo, Utah), instituição de orientação mórmon. Em grande medida, ele foi o responsável por aproximar Smith da sociologia, orientando suas primeiras pesquisas em comunidades rurais (Nelson, 1973). Whetten havia sido igualmente aluno de Nelson em Brigham Young. Antes de se tornar professor da Universidade Estadual de Connecticut, cursou a pós-graduação ao lado de Smith na Universidade de Minnesota. Os três possuíam origens sociais semelhantes, ligadas ao movimento de fixação de pequenos fazendeiros mórmons no Oeste dos EUA.

9. Em seu doutorado, Leonard havia realizado estudo sobre dos efeitos do padrão de divisão da terra prevalecente em El Cerrito, vila hispano-americana do Novo México, sobre a organização das comunidades locais (Leonard, 1943).

10. Cf.: INTER-AMERICAN (1993); Silva (2009).

11. Durante a guerra, Smith colaborou estreitamente com o governo da Colômbia e com intelectuais daquele país, que propunham ambiciosos planos de engenharia social para fomentar a formação de uma classe média rural a partir da atividade agropecuária (Lorek, 2013).

12. Antigo aluno de Carl Taylor no North Carolina Agricultural College e com doutorado em Harvard, para onde se dirigira no início dos anos 1930 a fim de acompanhar as aulas de Pitirim Sorokin, Loomis integrava os quadros da Division of Farm Population and Rural Welfare, chefiada por Taylor, quando foi convidado, no início de 1943, para conduzir investigações na estação agrícola experimental de Tingo María, no Peru, especializada no cultivo e extração de matérias primas para fabricação de borracha e quinina.

13. Além destas obras de fôlego, diversos estudos tratando de tópicos específicos da sociedade e da população rural, ou enfocando pequenas áreas do território nacional, foram desenvolvidos por Smith em El Salvador, por Nathan Whetten na Guatemala, por Olen 
Leonard no Equador e na Bolívia e por Charles Loomis no Peru e na Costa Rica. Cf.: Loomis et al. (1945); Leonard (1947).

14. Segundo Nisbet (1965), como reação aos processos de centralização político-administrativa e de burocratização e impessoalização crescentes da modernidade, ideais de comunidade vieram à tona na produção de vários ramos das ciências humanas, da filosofia e das artes nesse período.

15. Segundo Loomis (1940), os agricultores norte-americanos davam provas de que não mantinham relações estreitas com a terra ou com a comunidade, o que podia explicar os insucessos dos projetos de colônias agrícolas baseadas em cooperativas familiares implementados pelo New Deal.

16. Entre exemplos conhecidos de norte-americanos que produziram imagens positivas a respeito da América Latina, ou ibérica, pensada como um outro Ocidente, encontram-se Waldo Frank e Richard Morse, este último autor de O Espelho do Próspero. Sobre Waldo Frank, conferir: Pike (1985) e Tota (2000).

17. Mereceu a atenção dos norte-americanos o sistema de ejidos, modelo de redistribuição inspirado nas tradições das populações indígenas e mestiças e baseado na posse comunal da terra.

18. No caso dos livros produzidos pelos sociólogos rurais sobre diferentes países latino-americanos é interessante observar que, pretendendo fornecer um retrato amplo dessas sociedades, as obras acabavam se aproximando das perspectivas de conjunto que orientaram os ensaios de interpretação nacional de autores da região. Ao recorrerem, na expressão de Carl Taylor, às "origens do povo" e à "história do desenvolvimento do país" em questão, no esforço de compreender seus problemas, as análises dos sociólogos rurais contrastavam com os estudos sincrônicos e a-históricos que, via de regra, eles haviam se habituado a conduzir nos EUA, como as pesquisas empíricas com base em trabalho de campo intensivo, circunscritas a pequenas áreas, e as análises estatísticas apoiadas em amostragem. A leitura de "tratados escritos por cientistas sociais do país visitado" foi um passo importante para que as observações de campo adquirissem “precisão, ou mesmo lógica” (Taylor, 1960: 3).

19. Recentemente, abordagens globais e transnacionais no estudo da produção sociológica e antropológica do passado têm assinalado uma série de elementos (debates político-intelectuais, tradições disciplinares, circuitos e redes internacionais de atores e instituições, etc.) que, não pertencendo exclusivamente a um contexto nacional particular, conformaram contextos ou espaços intelectuais mais amplos, não passíveis de apreensão pelas molduras analíticas tradicionais, fornecidas pelo Estado-Nação. Note-se, contudo, que tais trocas intelectuais entre o Norte e o Sul globais não resultaram necessariamente nos mesmos ganhos para seus autores, situados em distintas partes do globo, em termos de circulação e reconhecimento. Cf.: Maia (2014); Maio e Lopes (2017); Rosemblatt (2014).

20. É possível reconstituir o itinerário de Smith a partir do minucioso e circunstanciado registro de suas despesas de viagem para o Departamento de Estado. Cf: T. Lynn Smith Papers (University of New Mexico, Center for Southwest Researh), doravante TLSP, Box 11, Folders 26 and 27.

21. A obra de Oliveira Vianna despertou reações diversas, desde rejeição à aprovação, que variaram de acordo com o contexto de recepção de seus trabalhos. Cf.: Santos (1978), Bastos e Moraes (1993), Werneck Vianna (1997), Botelho (2010), Bittencourt (2013) e Brasil Jr. (2017). 
Neste artigo não consideramos o conjunto da obra de Oliveira Vianna, mas apenas certas proposições que conformaram chaves de leitura do país mais ou menos recorrentes.

22. Ao analisar em perspectiva transnacional as reflexões de Oliveira Vianna em torno do corporativismo, Teixeira (2018) assinalou o diálogo que o autor estabeleceu com estudiosos do direito norte-americano simpáticos ao ímpeto reformador do governo Roosevelt. Esses intelectuais buscavam um arcabouço jurídico e teórico para um sistema político (o New Deal) pensado como alternativa tanto ao antigo liberalismo do laissez-faire quanto aos denominados totalitarismos do velho mundo. 


\section{REFERÊNCIAS}

BASTOS, Élide Rugai; MORAES, João Quartim de (orgs.). (1993), O Pensamento de Oliveira Vianna. Campinas, Editora da Unicamp.

BERGER, Mark. (1995), Under Northern Eyes: Latin American Studies and US Hegemony in the Americas, 1898-1990. Indianapolis, Indiana University Press.

BITTENCOURT, André Veiga. (2013), O Brasil e Suas diferenças: Uma Leitura Genética de Populações Meridionais do Brasil. Rio de Janeiro, Hucitec.

BOTELHO, André. (2010), “Passado e Futuro das Interpretações do País”. Tempo social, vol. $22, \mathrm{n}^{\circ} 1$, pp. 47-66.

BRASIL JR., Antônio da Silveira. (2017), “La Sociología en Río de Janeiro (1930-1970): Un Debate Sobre Estado, Democracia Y Desarrollo". Sociológica, vol. 32, nº 90, pp. 69-107.

BRINGEL, Breno. (2016), “Pensamento Crítico Latino-Americano e Pesquisa Militante em Orlando Fals Borda: Práxis, Subversão E Libertação". Direito \& Práxis, vol. 7, n 13, pp. 389-413.

BRUNNER, Edmund (1957). The Growth of a Science: a half-century of rural sociological research in the United States. New York, Harper.

BURSLEY, Herbert. (1941), [Department of State, Division of the American Republics] [Memorando] 15 set. 1941, Washington D.C. [para] SHAW, Howland, Washington D.C. 2f. National Archives and Records Administration, College Park, Maryland (NARA), Record Group 59, General Records of the Department of State. 1940-1944. Central Decimal File. Box 280, Folder 121.58/81.

CAMPOS, André. (2006), Políticas Internacionais de Saúde na Era Vargas: o Serviço Especial de Saúde Pública, 1942-1960. Rio de Janeiro, Ed. Fiocruz.

CARVALHO, Lucas Correia. (2015), Projeto, Conhecimento e Reflexividade: Estudos Rurais e Questão Agrária no Brasil dos Anos 1970. Tese (Doutorado em Sociologia), Instituto de Filosofia e Ciências Sociais, Universidade Federal do Rio de Janeiro, Rio de Janeiro.

CARVALHO, José Murilo de. (1993), “A utopia de Oliveira Vianna”, in E. R. Bastos e J. Q. Moraes (orgs.), O pensamento de Oliveira Vianna. Campinas, Editora da Unicamp, pp. 13-42.

CASTRO, Afonso Peter. (2010), "Collaborative Researchers or Cold Warriors? The Origins, Activities, and Legacy of the Smithsonian's Institute of Social Anthropology". Journal of Global and International Studies, vol. 2, nº 1, pp. 56-82.

COMMITTEE ON INTER-AMERICAN Cooperation in Agricultural Education. (1940), Minutes of the Meeting of November 7, 1940. Washington D.C.: Department of Agriculture. NARA, Record Group 166, General Correspondence of the Office of Foreign Agricultural Relations. 1942-49. Box 16, Folder "Education 1".

CHRISTY, Donald H. (1942), [Acting Director, Office of Foreign Agricultural Relations] [Memorando] 14 jan. 1942, Washington D.C. [para] Departamento de Estado. 1f. NARA, Record Group 59, General Records of the Department of State. 1940-1944. Central Decimal File. Box 248, Folder 120.31 Auxiliary/A --- 49A. 
CRONSHAW, Francine. (1982), "Exporting Ideology: T. Lynn Smith in Colombia”. Northsouth, vol. $7, \mathrm{n}^{\circ} 13$, pp. 95-109.

CUVI, Nicolás. (2011), “'Deje Que el Diablo Haga lo Demás': La Promoción de Productos Complementarios em América Latina Durante la Década de 1940". Historia Critica, $\mathrm{n}^{\circ} 44$, pp. 158-181.

ENGERMAN, David; GILMAN, Nils; HAEFELE, Mark; LATHAM, Michael (eds.) (2003), Staging Growth: Modernization, Development, and the Global Cold War. Amherst, University of Massachusetts Press.

ESCOBAR, Arturo. (2007), La Invención del Tercer Mundo. Construcción y Deconstrucción del desarrollo. Caracas, Fundación Editorial El Pero y La Rana.

ESPINOSA, José Manuel. (1977), Inter-American beginnings of U.S. Cultural Diplomacy: 19361948. Washington, Department of State.

ESTADOS UNIDOS. (1943), Memorandum of agreement between the Office of Foreign Agricultural Relations and the Bureau of Agricultural Economics, United States Departament of Agriculture, 15 out. 1943. 3f. NARA, Record Group 166, General Correspondence of the Office of Foreign Agricultural Relations. 1942-1949. Box 38, Projects - Rural Sociology; ALLEE, Ralph H. [Chief, Division of Latin American Agriculture, OFAR] [Carta] 16 out., Washington D.C. [para] TAYLOR, Carl, Washington D.C. 2f. Idem. Box 19, Extension Work.

FAULHABER, Priscila. (2011), “O Instituto de Antropologia Social (EUA, Brasil e México): Um Artefato da Resposta Antropológica ao 'Esforço De Guerra'”. Mana, vol. 17, nº 1, 9-39.

FERES JR., João. (2005), A história do conceito de Latin America nos Estados Unidos. Bauru, Edusc.

FIGUEIREDO, Regina Érika Domingos de. (2009), Histórias de uma Antropologia da "Boa Vizinhança": um Estudo sobre o Papel dos Antropólogos nos Programas Interamericanos de Assistência Técnica e Saúde no Brasil e no México (1942-1960). Tese (Doutorado em Antropologia), Instituto de Filosofia e Ciências Humanas, Universidade de Campinas, Campinas.

GALPIN, Charles J. (1915), The Social Anatomy of an Agricultural Community. Agricultural Experiment Station of the University of Wisconsin, Madison, Research Bulletin n⿳3 34, May.

GILBERT, Jess. (2015), Planning Democracy: Agrarian Intellectuals and the Intended New Deal. New Heaven, Yale University Press.

GILMAN, Nils. (2003), Mandarins of the Future: Modernization Theory in Cold War America. Baltimore, John Hopkins University Press.

GRAHAM, Sarah Ellen. (2015), Culture and Propaganda. The Progressive Origins of American Public Diplomacy, 1936 - 1953. Farnham, Ashgate.

HENNINGSON, Berton. (1981), United States Agricultural Trade and Development Policy During World War II: The Role of the Office of Foreign Agricultural Relations. Thesis (Ph.D in History), University of Arkansas, Arkansas.

IMMERWAHR, Daniel. (2015), Thinking Small: The United States and the Lure of Community Development. Cambridge, Harvard University Press.

INTER-AMERICAN Institute for Cooperation on Agriculture. (1993), IICA: 50 Years of History. San Jose, Costa Rica, IICA. 
KIRKENDALL, Richard. (1966), Social Scientists and Farm Politics in the Age of Roosevelt. Columbia, University of Missouri Press.

KREIMER, Pablo; ZABALA, Juan. (2006), “Qué Conocimiento y Para Quién? Problemas Sociales, Producción y Uso Social de Conocimientos Científicos Sobre la Enfermedad de Chagas em Argentina". Redes, vol. 12, no 23, pp. 49-78.

LARSON, Olaf; ZIMMERMAN, Julie. (2003), Sociology in Government: The Galpin-Taylor Years in the US Department of Agriculture, 1919-1953. University Park, Pennsylvania State University Press.

LATHAM, Michael. (2000), Modernization as Ideology: American Social Science and "Nation Building" in the Kennedy Era. Chapel Hill, University of North Carolina Press.

. (2011), The Right Kind of Revolution: Modernization, Development, and U.S. Foreign Policy from the Cold War to the Present. Ithaca, Cornell University Press.

LEONARD, Olen E. (1943), The Role of the Land Grant in the Social Organization and Social Processes of a Spanish-American Village in New Mexico. Thesis (Ph.D in Sociology), Louisiana State University, Louisiana.

. (1947), "Pichilingue: A Study of Rural Life in Coastal Ecuador". Foreign Agriculture Report, $\mathrm{n}^{\circ}$ 7. Office of Foreign Agricultural Relations, Washington D.C.

LESSER, Alexander. (1946), Survey of Research on Latin America. Committee on Latin American Anthropology, Division of Anthropology and Psychology. National Research Council, Washington D. C., pp. 75-82

LOOMIS, Charles. (1939), "Informal Social Participation in the Planned Rural Communities". Sociometry, vol. 2, $\mathrm{n}^{\circ}$ 4, pp. 1-37.

(1940), "Rebuilding American Community Life". American Sociological Review, vol. 5, $\mathrm{n}^{\circ} 3$, pp. 311-324.

. (1943), Extension work at Tingo Maria, Peru. 28 dez. 1943. National Archives and Records Administration, College Park (Maryland), Record Group 166, General Correspondence of the Office of Foreign Agricultural Relations. 1942-1949.

. (1979), An SfAA Oral History Interview with Charles P. Loomis. [Entrevista concedida a] Thomas May e Peter K. New. SfAA Oral History Project. Disponível em: <https:// www.appliedanthro.org/application/files/3515/6165/2747/Charles_Loomis.pdf $>$. Acesso em: 15 mai. 2021.

LOOMIS, Charles (1945), "Rural sociologists in Latin America". Applied Anthropology, vol. 4, $\mathrm{n}^{\circ} 4$, pp. 50-52.

LOPES, Thiago da Costa. (2020), Em Busca da Comunidade: Ciências Sociais, Desenvolvimento Rural e Diplomacia Cultural nas Relações Brasil-EUA (1930 - 1950). Rio de Janeiro, Ed. Fiocruz.

LOPES, Thiago da Costa; MAIO, Marcos Chor. (2017), "Comunidade e Democracia na Sociologia de T. Lynn Smith e José Arthur Rios". Revista Brasileira de Ciências Sociais, vol. 32, no 95, pp.1-21. 
LOREK, Timothy W. (2013), "Imagining the Midwest in Latin America: US Advisors and the envisioning of an agricultural middle class in Colombia's Cauca Valley, 1943-1946". The Historian, vol. 5, nº 2, pp. 283-305.

MAIA, João Marcelo Ehlert. (2014), "History of sociology and the quest for intellectual autonomy in the Global South: the cases of Alberto Guerreiro Ramos and Syed Hussein Alatas". Current Sociology, vol. 62, nº 7, pp. 1097-1115.

MAIO, Marcos Chor; OLIVEIRA, Nemuel da Silva; LOPES, Thiago da Costa. (2013), “Donald Pierson e o Projeto do Vale do Rio São Francisco: Cientistas Sociais em Ação na Era do Desenvolvimento". Dados, vol. 56, n 2, pp. 245-284.

MAIO, Marcos Chor; LOPES, Thiago da Costa. (2017) “Entre Chicago e Salvador: Donald Pierson e o Estudo das Relações Raciais". Estudos Históricos, vol. 30, nº 60, pp. 115-140.

MAIO, Marcos Chor. (2019), "Amazônia, Desenvolvimento e Relações Raciais na Antropologia de Charles Wagley (1940-1950)". Revista de História, n 178, p. 1-31.

MOORE, Ross. (1944), [Carta] 18 jan., Washington D.C. [para] WILSON, M. L., Washington D.C. 1f. NARA, Record Group 166, General Correspondence of the Office of Foreign Agricultural Relations. 1942-1949. Box 38, Projects-Rural Sociology 2.

. (1944), [Carta] 21 jan., Washington D.C. [para] HINES, Lee [Director, Estacion Experimental Agricola del Ecuador], Quito. 1f. NARA, Record Group 166, General Correspondence of the Office of Foreign Agricultural Relations. 1942-1949. Box 38, Projects - Rural Sociology 2.

MORENO, Mónica Cecilia. (2017), Orlando Fals Borda: Ideas, Prácticas y Redes, 1950- 1972. Tese (Doctorado en Ciencias Humanas y Sociales), Centro de Estudios Sociales, Facultad de Ciencias Humanas y Sociales, Universidad Nacional de Colombia, Bogotá.

MOURA, Gerson (2012), Relações Exteriores do Brasil: Mudanças na Natureza das Relações Brasil-Estados Unidos Durante e Após a Segunda Guerra Mundial. Brasília, Fundação Alexandre de Gusmão.

NELSON, Lowry. (1969), Rural Sociology: Its Origin and Growth in the United States. Minneapolis, University of Minnesota Press.

. (1967), "Rural Sociology: Some Inter-American Aspects". Journal of Inter-American Studies, vol. 9, n 3, pp. 323-338.

. (1973), Eighty: One Man's Way There. A memoir by Lowry Nelson. Mimeo., abril de 1973. T. Lynn Smith Papers (Center for Southwest Research, University of New Mexico), Box 16, Folder 28.

NINKOVICH, Frank A. (1981), The Diplomacy of Ideas: U.S. Foreign Policy and Cultural Relations, 1938-1950. London, Cambridge University Press.

NISBET, Robert A. (1965 [1953]), Community and Power. New York, The Oxford University Press.

OLIVEIRA VIANNA, Francisco José de. (1938 [1920]), Populações meridionais do Brasil. $4^{\text {a }}$ ed., São Paulo, Companhia Nacional. 
OLIVEIRA, Nemuel. (2010), Estudos de Comunidade, Ciências Sociais e Saúde: o Ciclo de Pesquisas no Vale do São Francisco na Década de 1950. Dissertação (Mestrado em História das Ciências e da Saúde), Fundação Oswaldo Cruz, Rio de Janeiro.

OLSSON, Tore C. (2017), Agrarian Crossings: Reformers and the Remaking of the U.S. and Mexican Countryside. Princeton; Oxford, Princeton University Press.

PARK, Robert; BURGESS, Ernest. (1967 [1925]), The City. Chicago, The University of Chicago Press.

PATEL, Kiran Klaus. (2016), The New Deal: A Global History. Princeton and Oxford: Princeton University Press.

PIERSON, Donald (1987). "Depoimento: Algumas Atividades no Brasil em Prol da Antropologia e Outras Ciências", in M. Corrêa (org.), História da Antropologia no Brasil: 1930-1960. Testemunhos: Emílio Willems e Donald Pierson. São Paulo, Vértice, pp. 29 - 116.

PIKE, Fredrick B. (1985), "Latin America and the Inversion of United States Stereotypes in the 1920s and 1930s: the Case of Culture and Nature". The Americas, vol. 43, n 2, pp. 131-162.

PRICE, David H. (2008), Anthropological Intelligence. The Development and Neglect of American Anthropology in the Second World War. Durham; London, Duke University Press.

RAPER, Arthur. (1954), "Rural Sociologists and Foreign Assignments”. Rural Sociology, vol. 18, $\mathrm{n}^{\circ} 3$, pp. 264-266.

REDFIELD, Robert. (1930), Tepoztlán: a Mexican Village (A Study of Folk Life). Chicago; London, The University of Chicago Press.

RIST, Gilbert. (1997), The History of Development: From Western Origins to Global Faith. London, Zed Books.

ROSEMBLATT, Karin Alejandra. (2014), "Modernization, Dependency, and the Global in Mexican Critiques of Anthropology". Journal of Global History, vol. 9, n 1, pp. 94-121.

SALVATORE, Ricardo D. (2016), Disciplinary Conquests: U.S. Scholars in South America, 1900-1945. Durhman, Duke University Press.

SANTOS, Wanderley Guilherme dos. (1978), "Paradigma e História: a Ordem Burguesa na Imaginação Social Brasileira", in W. G. Santos, Ordem Burguesa e Liberalismo Político. Duas Cidades, São Paulo.

SHAPIN, Steven. (2008), The Scientific Life: A Moral History of a Late Modern Vocation. Chicago; London, The University of Chicago Press.

SHAW, Howland. (1941), Memorandum of Conversation with Dr. Louis G. Michael. 19 set. $2 \mathrm{f}$. NARA, Record Group 59, General Records of the Department of State. 1940-1944. Central Decimal File. Box 280, Folder 121.58/81.

SILVA, Claiton Marcio da. (2009), Agricultura e Cooperação Internacional: A Atuação da American International Association for Economic and Social Development (AIA) e os Programas de Modernização do Brasil (1946 - 1961). Tese (Doutorado em História das Ciências e da Saúde), Fundação Oswaldo Cruz, Rio de Janeiro.

SMITH, Richard Cándida. (2017), Improvised Continent: Pan-Americanism and Cultural Exchange. Philadelphia, University of Pennsylvania Press. 
SMITH, T. Lynn. (1935), "The Social Effects of Land Division in Relationship to a Program of Land Utilization". Journal of Farm Economics, vol. XVII, nº 4, pp. 702-709.

.(1940a), Exchange of Professors and Students. T. Lynn Smith Papers (Center for Southwest Research, University of New Mexico), Box 1, Folder 77.

. (1940b), The Sociology of Rural Life. New York; London, Harper and Brothers.

. (1941), "The Role of the Community in American Rural Life". Journal of Educational Sociology, vol. 14, $\mathrm{n}^{\circ}$ 7, pp. 387-400.

. (1942a), Field Notes. T. Lynn Smith Papers (Center for Southwest Research, University of New Mexico), Box 10, Folder 18.

. (1942b), Field Notes. T. Lynn Smith Papers (Center for Southwest Research, University of New Mexico), Box 7, Folder 55.

. (1942c), Japanese Immigration and the Number and Distribution of Japanese Population in the State of Sao Paulo, Brazil. NARA, Record Group 166, Records of the Foreign Agricultural Service, Narrative Reports, 1942-1945, Brazil, Agriculture, Box 5, Folder 1942-1943.

. (1943a), The Brazilian Labor Force in Relation to Agriculture. Confidential Report, 20 jan. NARA, Record Group 166, Records of the Foreign Agricultural Service, Narrative Reports, 1942-1945, Brazil, Agreement - Labor, Box 80, Folder Restricted 1942-1945 Labor.

. (1943b), Brazil: The Population and the Relations of the People to the Land. Washington, United States Department of Agriculture, Office of Foreign Agricultural Relations, Aug. 20. T. Lynn Smith Papers (Center for Southwest Research, University of New Mexico), Box 8, Folder 30.

. (1944), "The Locality Group Structure of Brazil". American Sociological Review, vol. 9, no 1 , pp. 41-40.

. (1946), Brazil: People and Institutions. Baton Rouge, Louisiana State University Press.

. (1952), Memorando ao Senhor João Cleofas, Ministro da Agricultura, Presidente da Comissão Nacional de Política Agrária. Rio de Janeiro, 16 set. T. Lynn Smith Papers (Center for Southwest Research, University of New Mexico), Box 3, Folder 74.

. (1957), "Rural Sociology in the United States and Canada: A Trend Report". Current Sociology, vol. 6 , $\mathrm{n}^{\circ} 1$, pp. 5-18.

. (1973), How I Became a Rural Sociologist. T. Lynn Smith Papers (Center for Southwest Research, University of New Mexico), Box 2, Folder 61.

. (1974), "The development of Rural Sociology in the United States, with a few Annotations on its Development in the South", in J.E. Dunkelberger e J.B. Vanlandingham (eds.), Reflections on the development of cooperative rural sociology research in the South. Auburn, Auburn Agricultural Experiment Station, pp. 3-18.

SMITH, Dennis. (1988), The Chicago School: A Liberal Critique of Capitalism. New York, St. Martin's Press.

TAYLOR, Carl. (1942), [Carta] 8 maio, Buenos Aires [para] SMITH, T. Lynn., Rio de Janeiro e WHETTEN, Nathan, Cidade do México. 8f. TLSP, Box 15, Folder 3. 
. (1944), "Rural Locality Groups in Argentina". American Sociological Review, vol. 9, $\mathrm{n}^{\mathrm{o}} 2$, pp. 170.

(1948), Rural Life in Argentina. Baton Rouge, Louisiana State University Press.

. (1960), "Early Rural Sociological Research in Latin America". Rural Sociology, vol. 25, $\mathrm{n}^{\mathrm{o}} 1$, pp.1-8.

TEIXEIRA, Melissa. (2018), "Making a Brazilian New Deal: Oliveira Vianna and the Transnational Sources of Brazil's Corporatist Experiment". Journal of Latin American Studies, vol. 50, n 3, pp. 613-641.

TOTA, Antonio Pedro. (2000), O Imperialismo Sedutor: AAmericanização do Brasil na Época da Segunda Guerra. São Paulo, Companhia das Letras.

WALLACE, Henry A. (1940), "Inter-American Agricultural Cooperation”. Foreign Agriculture, vol. IV, nº 5, pp. 275-286.

WILCOX, Clifford. (2006), Robert Redfield and the Development of American Anthropology. United Kingdom, Lexington Books.

WHEELER, Leslie Allen. (s./d), The Department of Agriculture and Its Relation to the Foreign Service. 15f. Sem data. NARA, Record Group 166, General Correspondence of the Office of Foreign Agricultural Relations, 1942-49, Box 68, Folder "Public Relations 8 - Speeches-Lectures".

WERNECK VIANNA, Luiz. (1997), A Revolução Passiva: Iberismo e Americanismo no Brasil. Rio de Janeiro, Revan.

WHETTEN, Nathan. (1948), Rural Mexico. Chicago; London, The University of Chicago Press, 1948.

WILSON, Milburn. L. (1940), "The Democratic Processes and the Formulation of Agricultural Policy". Social Forces, vol. 19, n 1, pp. 1-11.

ZIMMERNMAN, Carle. (1930), Farm Trade Centers in Minnesota, 1905-1929: a Study in Rural Social Organization. St. Paul: University of Minnesota, Agricultural Experimental Station, Bulletin 269. 


\title{
RESUMO
}

Sociólogos rurais, modernização e ideais de comunidade na América Latina: o caso do Office of Foreign Agricultural Relations (1930 - 1940)

O artigo aborda a participação de sociólogos rurais norte-americanos em missões técnicas na América Latina, durante a Segunda Guerra Mundial, como parte dos programas de cooperação interamericana dos EUA. Argumenta que o contexto político e intelectual da Era Roosevelt, assim como a matriz comunitarista de pensamento da sociologia rural, contribuíram para que esses cientistas sociais lançassem um olhar particular sobre os vizinhos ao Sul do Rio Grande. Esses povos foram concebidos não apenas como economicamente atrasados, mas também como lócus de experimentos societais originais que poderiam, no curso de seu desenvolvimento, contornar aqueles que eram considerados os efeitos deletérios da modernização capitalista nos EUA, como o individualismo dissolvente dos laços comunitários. Focalizando o caso de T. Lynn Smith, que atuou como analista agrícola no Brasil e na Colômbia, indica como tal diagnóstico sobre os potenciais de desenvolvimento da América Latina envolveu igualmente diálogos com tradições locais de pensamento.

Palavras-chave: Escritório de Relações Agrícolas Estrangeiras; Modernização; Sociologia Rural; América Latina; T. Lynn Smith.

\begin{abstract}
Rural Sociologists, Modernization, and Community Ideals in Latin America: The Case of the Office of Foreign Agricultural Relations (1930-1940)

In this article, we discuss the participation of US rural sociologists in technical missions in Latin America during World War II as part of the Inter-American cooperation programs under the Office of Foreign Agricultural Relations. We argue that the political and intellectual context of the Roosevelt Era as well as the communitarian thought style that informed these social scientists shaped a vision of their neighbors to the South not only as economically backward but as the locus of original societal experiments that could, in the course of its development, circumvent those that were considered the deleterious effects of modernization in the US, such as the dissolving individualism and the weakening of community ties. Focusing on the case of T. Lynn Smith, who served as an agricultural analyst in Brazil and Colombia, we indicate how such a sociological diagnosis of Latin America's development potentials also involved dialogues with local thinking traditions.
\end{abstract}

Keywords: Office of Foreign Agricultural Relations; Modernization; Rural Sociology; Latin America; T. Lynn Smith. 


\section{RÉSUMÉ}

Sociologues ruraux, modernisation et idéaux communautaires dans l'Amérique Latine: Le Cas de l'Office of Foreign Agricultural Relations (1930-1940)

Dans cet article, nous discutons de la participation de sociologues ruraux américains à des missions' techniques en Amérique Latine pendant la Seconde Guerre Mondiale dans le cadre des programmes de coopération interaméricaine de l'Office of International Agricultural Relations du Ministère Américain de l'Agriculture. Nous soutenons que le contexte politique et intellectuel de l'ère Roosevelt ainsi que la matrice de pensée communautaire en Sociologie Rurale ont contribué à ce que ces sociologues voient les voisins méridionaux du continent non seulement comme économiquement arriérés, mais comme le locus d'expériences sociétales originales qui pourraient, au cours de son développement, contourner ceux qui étaient considérés comme les effets délétères de la modernisation capitaliste aux États-Unis, comme l'individualisme qui dissout les liens communautaires. En nous concentrant sur le cas de T. Lynn Smith, qui a travaillé comme analyste agricole au Brésil et en Colombie, nous indiquons comment un tel diagnostic sociologique des potentiels de développement de l'Amérique Latine a impliqué également des dialogues avec les traditions de pensée locales.

Mots-clés: Bureau des Relations Agricoles Étrangères; Modernisation; Sociologie Rurale; Amérique-Latine; T. Lynn Smith.

\section{RESUMEN}

Sociólogos rurales, modernización e ideales de comunidad en América Latina: el caso de la Office of Foreign Agricultural Relations (1930 - 1940)

En este artículo, abordamos la participación de sociólogos rurales norteamericanos en misiones técnicas en América Latina durante la Segunda Guerra Mundial como parte de los programas de cooperación interamericana de la Oficina de Relaciones Agrícolas Internacionales del Departamento de Agricultura de Estados Unidos. Argumentamos que el contexto político e intelectual de la Era Roosevelt, así como la matriz comunitarista de pensamiento de la sociología rural, contribuyeron a que esos científicos sociales observaran a los vecinos al Sur del continente no solamente como económicamente atrasados, sino también como lócus de experimentos societales originales que podrían, en el curso de su desarrollo, contornar lo que eran considerados como los efectos perjudiciales para la modernización capitalista en Estados Unidos, como el individualismo disolvente de los lazos comunitarios. Tomando el caso de T. Lynn Smith, que ejerció como analista agrícola en Brasil y Colombia, indicamos como tal diagnóstico sociológico sobre los potenciales de desarrollo de América Latina involucró igualmente diálogos con tradiciones locales de pensamiento.

Palabras clave: Oficina de Relaciones Agrícolas Extranjeras; Modernización; Sociología Rural; América Latina; T. Lynn Smith. 